\title{
Intracellular flow cytometry staining of antibody-secreting cells using phycoerythrin- conjugated antibodies: pitfalls and solutions
}

3 Patrick Renner $^{c_{\dagger}^{\dagger}}$, Michael Crone ${ }^{\mathrm{c} \dagger}$, Matthew Kornas ${ }^{\mathrm{c} \dagger}$, KimAnh T. Pioli ${ }^{\mathrm{a}, \mathrm{b}, \mathrm{c}}$ Peter D. Pioli $^{\mathrm{a}, \mathrm{b}, \mathrm{c}^{*}}$

$4 \quad{ }^{\mathrm{a}}$ Center for Immunobiology, ${ }^{\mathrm{b}}$ Department of Investigative Medicine, ${ }^{\mathrm{c}}$ Western Michigan University

5 Homer Stryker M.D. School of Medicine, 1000 Oakland Drive, Kalamazoo, MI, 49008 United States

6 †These authors share first authorship.

7 * Correspondence:

8 Peter D. Pioli

9 peter.pioli@med.wmich.edu

10 petepioli@gmail.com 
bioRxiv preprint doi: https://doi.org/10.1101/2022.01.10.475671; this version posted January 11, 2022. The copyright holder for this preprint (which was not certified by peer review) is the author/funder. All rights reserved. No reuse allowed without permission. Antibody-secreting cell intracellular flow

\section{Abstract}

13 Antibody-secreting cells are terminally differentiated B cells that play a critical role in humoral 14 immunity through immunoglobulin secretion along with possessing the potential to be long-lived. It is 15 now appreciated that antibody-secreting cells regulate multiple aspects of biology through the secretion 16 of various cytokines. In this regard, intracellular flow cytometry is a key tool used to assess the presence 17 of intracellular proteins such as cytokines and transcription factors. Here, we showed that the use of 18 phycoerythrin-containing antibody conjugates led to a false interpretation of antibody-secreting cell 19 intracellular protein expression compared to other cell types. This was mainly due to the inappropriate 20 retention of these antibodies specifically within antibody-secreting cells. Furthermore, we 21 demonstrated how to reduce this retention which allowed for a more accurate comparison of 22 intracellular protein expression between antibody-secreting cells and other cell types such as B 23 lymphocytes. Using this methodology, our data revealed that spleen antibody-secreting cells expressed 24 Toll-like receptor 7 as well as the pro-form of the inflammatory cytokine interleukin-1 $\beta$.

25 Keywords: antibody-secreting cell, plasma cell, plasmablast, phycoerythrin, intracellular flow 26 cytometry 
bioRxiv preprint doi: https://doi.org/10.1101/2022.01.10.475671; this version posted January 11, 2022. The copyright holder for this preprint (which was not certified by peer review) is the author/funder. All rights reserved. No reuse allowed without permission. Antibody-secreting cell intracellular flow

\section{Introduction}

29

30

31

32

33

34

35

36

37

38

39

40

41

42

43

44

Humoral, or antibody (Ab)-mediated, immunity plays a critical role in host defense (Amanna et al., 2007). Through a variety of mechanisms, the activation of $B$ cells can lead to their terminal differentiation into antibody-secreting cells (ASCs) which include relatively short-lived plasmablasts (PBs) as well as more mature plasma cells (PCs) (Fairfax et al., 2008; Gaudette and Allman, 2021; Manakkat Vijay and Singh, 2021; Nutt et al., 2015). In general, ASCs are viewed as critical effectors of humoral immunity through their potential to be long-lived (Landsverk et al., 2017; Manz et al., 1998) as well as their continuous production of Abs (Slifka et al., 1998).

It is now appreciated that ASCs have the ability to influence host biology well beyond the direct effects of Ab synthesis (Ma et al., 2020; McGettigan and Debes, 2021; Pioli, 2019). Given that ASCs are programmed for protein production and secretion (Shaffer et al., 2004; Zhu et al., 2019), it is not a surprise that many of the functions they exert are mediated by cytokine production. For example, ASCs utilize interleukin (IL)-10 to suppress the inflammatory response in the context of autoimmunity (Matsumoto et al., 2014; Rojas et al., 2019). However, ASCs can also facilitate the immune response through the production of factors including IL-6 (Chavele et al., 2015) as well as IL-3 (Chin et al., 2019) and granulocyte-macrophage colony-stimulating factor (GM-CSF) (Rauch et al., 2012; Weber et al., 2014).

Multiple strategies currently exist which allow for the evaluation of ASC cytokine production. For instance, ASCs can be isolated via fluorescence-activated cell sorting, stimulated in vitro and have culture supernatants directly probed for selected cytokines (Lino et al., 2018). While informative, this approach requires knowing the correct stimulus, or stimuli, and does not necessarily provide insight into the cytokines that ASCs are actively producing while residing within a particular tissue. As such, this type of analysis has been paired with in vivo techniques that utilize fluorescent reporter mice such as those specific for IL-10 (Lino et al., 2018; Matsumoto et al., 2014; Meng et al., 2019; Shen et al., 2014; Suzuki-Yamazaki et al., 2017). However, since genetically engineered reporter mice are not readily available for most cytokines, intracellular flow cytometry (ICFC) is also extensively performed to assess ASC cytokine production (Chin et al., 2019; Rauch et al., 2012; Weber et al., 2014). Indeed, this approach was recently used to show that plasmablasts produced IL-3 and GM-CSF in the context of malaria-inducing parasitic infections (Chin et al., 2019).

Within the field of flow cytometry, phycoerythrin (PE)-conjugated Abs are known to be extremely "bright" and provide large signal-to-noise ratios thus facilitating their use to detect rare protein targets (Batard et al., 2002). However, an under-appreciated study has previously shown that ASCs nonspecifically retain PE during ICFC (Kim and Kim, 2013). This artifact pertains to ex vivo stained ASCs and well as those derived in vitro. Very recently, non-specific PE retention was observed when ICFC was performed on day 3 cultures from lipopolysaccharide (LPS)-stimulated B cells (Bohacova et al., 2021), a timepoint known to generate a significant proportion of ASCs. Quite clearly, this retention phenomenon is a confounding factor in the analysis of ASC cytokine production and evaluation with ICFC.

In this study, we showed that the complication of non-specific PE retention by ASCs also pertained to PE-containing tandem fluorochromes such as PE/Cy7. Interestingly enough, the number of centrifugation steps post-fixation directly modulated the extent of this retention. Provided here is a standard approach that reduces PE retention thus allowing the use of PE- and PE/Cy7-conjugates Abs to perform ICFC on ASCs. Via this methodology, we demonstrated that spleen (SPL) ASCs possessed increased amounts of Pro-IL-1 $\beta$ compared to B220 ${ }^{+}$CD138- B cells (BCs) from the SPL. Furthermore, 
bioRxiv preprint doi: https://doi.org/10.1101/2022.01.10.475671; this version posted January 11, 2022. The copyright holder for this preprint (which was not certified by peer review) is the author/funder. All rights reserved. No reuse allowed without permission. Antibody-secreting cell intracellular flow

we detected TLR7 protein expression by ASCs thus adding to the growing list of immunomodulatory receptors that these cells possess.

\section{Methods}

\subsection{Mice}

B6.Cg-Tg(Prdm1-EYFP)1Mnz/J (Stock \#: 008828) and wildtype C57BL/6 mice were purchased from the Jackson Laboratory and used to establish a breeding colony within the vivarium of the Western Michigan University Homer Stryker M.D. School of Medicine (WMed). Wildtype mice were used for all experiments. Both females and males were used between 12-32 weeks of age for experiments in Figures 1-4 and Supplementary Figure 1. 25-weeks old males were specifically used in Figure 5 and Supplementary Figure 2 to correct for any potential age- or sex-based effects on target protein expression. All experiments were performed with the approval of the WMed Institutional Animal Care and Use Committee (IACUC).

\subsection{Isolation of spleen tissue}

SPLs were processed and collected in calcium and magnesium-free 1x phosphate buffered saline (PBS). Organs were crushed between the frosted ends of 2 slides and cell suspensions were centrifuged for 5 minutes at $4{ }^{\circ} \mathrm{C}$ and $600 \mathrm{~g}$. Red blood cells were lysed by resuspending (RSS) cells in $3 \mathrm{~mL}$ of $1 \mathrm{x}$ red blood cell lysis buffer on ice for $\sim 3$ minutes. Lysis was stopped with the addition of $7 \mathrm{~mL}$ of $1 \mathrm{x}$ PBS. Cell suspensions were counted via a hemocytometer using Trypan Blue to exclude dead cells and subsequently passed through $70-\mu \mathrm{m}$ filters, centrifuged as above and RSS in $1 \mathrm{x}$ PBS $+0.1 \%$ bovine serum albumin (BSA) at a concentration of $2 \times 10^{7}$ cells $/ \mathrm{mL}$ before use.

\subsection{Cell surface immunostaining for flow cytometry}

All cell surface staining procedures were performed in $1 \mathrm{x}$ PBS $+0.1 \%$ BSA using $\sim 5 \times 10^{6}$ cells per stain. Samples were labeled with a CD16/32 blocking Ab to eliminate non-specific binding of Abs to cells via Fc receptors. All Abs utilized are listed in the Supplementary Table 1. Cells were incubated on ice for 30 minutes with the appropriate Abs. Unbound Abs were washed away with $3 \mathrm{~mL}$ of $1 \mathrm{x}$ PBS $+0.1 \%$ BSA followed by centrifugation for 5 minutes at $4{ }^{\circ} \mathrm{C}$ and $600 \mathrm{~g}$. Supernatants were decanted. In certain instances, eBioscience Fixable Viability (Live-Dead) Dye eFluor 780 (Thermo Fisher Scientific, Catalog \# 65-0865-14) was added to samples to assess dead cell content. The stock solution was diluted 1:250 and $10 \mathrm{uL}$ was added to $\sim 5 \times 10^{6}$ cells per stain. Live-Dead stain was added concurrent with surface staining Abs.

\subsection{Paraformaldehyde and saponin immunostaining for intracellular flow cytometry}

Cells were surface stained as described above. Afterwards, cell pellets were RSS in $1 \mathrm{~mL}$ of $4 \%$ paraformaldehyde (PFA) and incubated at room temperature (RT) for 20 minutes in the dark. Subsequently, $2 \mathrm{~mL}$ of $1 \mathrm{x}$ PBS $+0.1 \% \mathrm{BSA}+0.1 \%$ Saponin (Sap) were added and cells centrifuged for 5 minutes at $4{ }^{\circ} \mathrm{C}$ and $600 \mathrm{~g}$. Supernatants were decanted and the previous wash step was repeated with $3 \mathrm{~mL}$ of $1 \mathrm{x}$ PBS $+0.1 \%$ BSA $+0.1 \%$ Sap for a total of 2 washes. Supernatants were discarded and cells were RSS in residual buffer $(\sim 150 \mu \mathrm{L})$. Unlabeled mouse IgG was added as a blocking reagent and cells were incubated at RT for 20 minutes in the dark. Subsequently, the appropriate Abs were added and cells were incubated at RT for 30 minutes in the dark. Afterwards, $3 \mathrm{~mL}$ of $1 \mathrm{x}$ PBS $+0.1 \%$ $\mathrm{BSA}+0.1 \%$ Sap were added and cells centrifuged for 5 minutes at $4{ }^{\circ} \mathrm{C}$ and $600 \mathrm{~g}$. Supernatants were decanted and cells were washed with $3 \mathrm{~mL}$ of 1x PBS $+0.1 \%$ BSA. Supernatants were discarded and 
bioRxiv preprint doi: https://doi.org/10.1101/2022.01.10.475671; this version posted January 11, 2022. The copyright holder for this preprint (which was not certified by peer review) is the author/funder. All rights reserved. No reuse allowed without permission.

Antibody-secreting cell intracellular flow

113 cell pellets were RSS in an appropriate volume of 1x PBS $+0.4 \%$ BSA +2 mM EDTA for flow

114 cytometric analysis. Before analysis, cells were strained through a $35 \mu \mathrm{M}$ filter mesh. Any deviation

115 from wash step constituents or sequence are noted in the Results section.

116 2.5. eBioscience Foxp3/Transcription Factor Staining Buffer Set immunostaining for 117 intracellular flow cytometry

118 For this procedure, ICFC was performed with the eBioscience Foxp3/Transcription Factor Staining 119 Buffer Set (Thermo Fisher Scientific, Catalog \# 00-5523-00). Cells were surface stained as described above. Afterwards, cell pellets were RSS in $1 \mathrm{~mL}$ of Buffer 1 and incubated at RT for 20 minutes in the dark. Subsequently, $2 \mathrm{~mL}$ of Buffer 2 were added and cells centrifuged for 5 minutes at $4{ }^{\circ} \mathrm{C}$ and $600 \mathrm{~g}$. Supernatants were decanted and the previous wash step was repeated with $2 \mathrm{~mL}$ of Buffer 2 for a total of 2 washes. Supernatants were discarded and cells were RSS in residual buffer $(\sim 150 \mu \mathrm{L})$. Unlabeled mouse IgG was added as a blocking reagent and cells were incubated at RT for 20 minutes in the dark. Subsequently, the appropriate Abs were added and cells were incubated at RT for 30 minutes in the dark. Afterwards, 2 mL of Buffer 2 were added and cells centrifuged for 5 minutes at 4 ${ }^{\circ} \mathrm{C}$ and $600 \mathrm{~g}$. Supernatants were decanted and cells were washed with $3 \mathrm{~mL}$ of $1 \mathrm{x}$ PBS $+0.1 \%$ BSA. Supernatants were discarded and cell pellets were RSS in an appropriate volume of $1 \mathrm{x}$ PBS $+0.4 \%$ BSA +2 mM EDTA for flow cytometric analysis. Before analysis, cells were strained through a 35 $\mu \mathrm{M}$ filter mesh. Any deviation from wash step constituents or sequence are noted in the Results section.

\subsection{Flow cytometry}

Flow cytometry was performed on a Fortessa (BD Biosciences) located in the Flow Cytometry and Imaging Core at WMed. Data were analyzed using FlowJo (v10) software. Total cells were gated using side scatter area (SSC-A) versus forward scatter (FSC-A) area. Singlets were identified using sequential gating of FSC-width (W) versus FSC-A, SSC-W versus SSC-A and FSC-height (H) versus FSC-A.

\subsection{Quantification and statistical analysis}

138 Technical and biological replicates are indicated in the Figure Legends.

\section{3. Results}

\subsection{Antibody-secreting cells preferentially retain phycoerythrin-conjugated antibodies}

ICFC of cytokines has become a critical tool used to evaluate ASC diversification and function. Using conventional fixation (i.e. PFA) and permeabilization (i.e. Sap) techniques, it has been reported that ASCs non-specifically retain PE-conjugated Abs thus making them unsuitable for ICFC (Kim and Kim, 2013). This was shown to be the case for ex vivo stained ASCs as well as those generated in vitro following B lymphocyte stimulation (Kim and Kim, 2013).

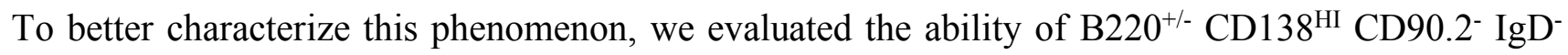
ASCs (Figure 1A) from the SPL to retain a variety of non-specific isotype control Abs conjugated to allophycocyanin (APC), PE and PE/Cy7. As a point of comparison, we also examined this capacity in SPL B220 ${ }^{+}$CD138- BCs (Figure 1A). For these experiments, we utilized hamster (ham) IgG, rat (r) $\mathrm{IgG} 1, \mathrm{rIgG} 2 \mathrm{a}$ and $\mathrm{rIgG} 2 \mathrm{~b}$ isotypes. Using flow cytometry, retention was measured as a function of geometric mean fluorescence intensity (gMFI). In this regard, increased gMFIs were indicative of increased retention (Supplementary Figures 1A-F). 
Abs conjugated to APC produced very little background when compared to fluorescence minus one (FMO) controls (Figure 1B and Supplementary Figure 1A). This was independent of concentration and observed in both BCs and ASCs. However, the examination of PE-conjugated isotype Abs painted a different picture. While BC and ASC FMO controls possessed similar amounts of PE-mediated background autofluorescence (Figure 1C and Supplementary Figure 1C), the use of low amounts $(0.04 \mu \mathrm{g})$ of PE-conjugated isotype Abs resulted in low but evident levels of retention in ASCs relative to BCs (Figure 1C and Supplementary Figure 1C). The use of increased Ab amounts $(0.20 \mu \mathrm{g})$ led to further retention by ASCs which was apparent for all isotypes (Figure 1C and Supplementary Figure 1C). To determine if these observations could be more generalized, we examined retention of the tandem dye PE/Cy7 (Figure 1D and Supplementary Figure 1E). Similar to PE, PE/Cy7 retention by ASCs was evident in a concentration-dependent manner regardless of isotype (Figure 1D and Supplementary Figure 1E).

Additionally, we subdivided ASCs (Figure 1A) into short-lived plasmablasts (PBs) and more mature, potentially long-lived, plasma cells (PCs) which are $\mathrm{B} 220^{+}$and B220-, respectively. Analysis of APC, $\mathrm{PE}$ - and $\mathrm{PE} / \mathrm{Cy} 7$-conjugated isotype $\mathrm{Ab}$ retention demonstrated a high degree of similarity between PBs and PCs (Figures 1B-D and Supplementary Figures 1B, 1D and 1F). These data indicated that maturation status of ASCs (PBs vs PCs) did not explicitly alter the capacity to retain PE- and PE/Cy7conjugated isotype Abs. Furthermore, these results suggested that potential contamination with nonASCs that possess B220 expression (e.g. plasmacytoid dendritic cells) did not heavily influence the data. In summary, ASCs displayed retention of PE-based fluorochromes that was independent of $\mathrm{Ab}$ isotype and species but was augmented by increased $\mathrm{Ab}$ amounts.

\subsection{The number of washes following paraformaldehyde fixation modulates antibody-secreting cell retention of phycoerythrin-conjugated antibodies}

In our staining protocol, we utilized one post-stain wash that included Sap (Figure 2A, brown). This was then followed by a wash with PBS $+0.1 \%$ BSA. Therefore, it is possible that additional Sap washes could abrogate $\mathrm{PE}$ retention. To test this, we performed experiments in which cells stained with rIgG2aPE $(0.20 \mu \mathrm{g})$ received 1,2 or 3 post-stain Sap washes followed by a terminal PBS $+0.1 \%$ BSA wash (Figures 2B-D). The number of post-stain Sap washes had essentially no effect on BC background PE staining (Figures 2B-C). The addition of a $2^{\text {nd }}$ or even $3^{\text {rd }}$ wash had only minor effect on PE retention by ASCs compared to cells that received a single wash (Figure 2D). The ASC / BC PE gMFI ratio (Figure 2D) ranged from $\sim 14-33$ regardless of the number of post-stain Sap washes. These data confirmed previous observations from studies in which multiple post-stain washes containing permeabilizing agents were ineffectively used to remove PE retention by ASCs (Bohacova et al., 2021; Kim and Kim, 2013).

The experiments presented in Figure 1 utilized 2 post-fixation washes with $0.1 \%$ Sap as part of a PBS $+0.1 \%$ BSA solution (Figure $\mathbf{2 A}$, red). While it is commonly appreciated that fixation method can alter immunostaining properties of cells (Matsuda et al., 2011), it is not readily known how the steps used to remove a fixative can alter immunostaining. To test this, we kept the $2^{\text {nd }}$ post-fixation wash constant and performed the $1^{\text {st }}$ wash with PBS $+0.1 \%$ BSA $+0.1 \%$ Sap (Sap/Sap), PBS + 0.1\% BSA (BSA/Sap) or PBS (PBS/Sap). Subsequently, we analyzed retention of rIgG2a-PE $(0.20 \mu \mathrm{g})$ by BCs and ASCs (Figure 2E). Regardless of $1^{\text {st }}$ wash composition, ASCs still retained rIgG2a-PE as shown by heightened PE gMFIs when compared to BCs (Figures 2E-F). Ultimately, rIgG2a-PE background was increased $\sim 30 \mathrm{x}$ in ASCs (Figure 2G). 
bioRxiv preprint doi: https://doi.org/10.1101/2022.01.10.475671; this version posted January 11, 2022. The copyright holder for this preprint (which was not certified by peer review) is the author/funder. All rights reserved. No reuse allowed without permission. Antibody-secreting cell intracellular flow

Since the number of post-stain Sap washes as well as post-fixation wash buffer composition did not appear to play a major role, we considered "physical" forces involved in ICFC that may augment ASC retention of PE. ASCs are complex cells whose cytoplasm is dominated by an extensive endoplasmic reticulum and Golgi network (Ribatti, 2017), which is quite a contrast to naive BCs. As such, the act of centrifugation and the forces imparted on BCs and ASCs may be different and thus lead to ASCspecific PE retention. Along these lines, variations in centrifugation protocols can have dramatic effects on recovery as well as viability of mechanically sensitive cells (Katkov and Mazur, 1999; Kim et al., 2009). To test this hypothesis, we repeated the above retention experiments using either 1,2 or 3 postfixation washes with PBS $+0.1 \%$ BSA $+0.1 \%$ Sap (Figure 2H). Increasing the number of washes slightly decreased the already low levels of rIgG2a-PE staining in BCs (Figures 2H-I). Amazingly, rIgG2a-PE $(0.20 \mu \mathrm{g})$ retention by ASCs was dramatically enhanced as more washes and subsequent centrifugation steps were performed (Figures 2H-I). When compared to BCs, the rIgG2a-PE staining of ASCs was near equivalence at 1 wash. At 2 washes, the ratio of ASC / BC PE gMFI was $\sim 25$ (Figure 2J) similar to what was previously shown in Figure 2D. Finally, the addition of a $3^{\text {rd }}$ wash dramatically increased this ratio to $>93$, on average (Figure 2J). To further assess the impact of "force" effects on PE retention, we performed experiments in which cells received either 1 or 2 post-fixation washes using a relative centrifugal force (RCF) of $600 \mathrm{~g}$ or $300 \mathrm{~g}$ (Figure $2 \mathrm{~K}$ ). If total RCF was a determining factor, ASCs which received single or multiple $300 \mathrm{~g}$ centrifugation steps would display less retention than their $600 \mathrm{~g}$ counterparts. Somewhat surprisingly, the level of PE retention observed in ASCs correlated with the number of centrifugation steps rather than the amount of RCF imparted on cells (Figure 2K). This was readily apparent when we quantified the gMFI of PE retention (Figure 2L) as well as the ratio of ASC / BC PE retention (Figure 2M). In both instances, ASCs washed twice routinely demonstrated increased levels of PE staining regardless of RCF. Taken in total, these results indicated that the physical act of washing cells post-PFA fixation was the most critical driver in ASC PE retention.

\subsection{The number of post-fixation washes modulates antibody-secreting cell retention of phycoerythrin-conjugated antibodies when using the eBioscience Foxp3/Transcription Factor Staining Buffer Set}

The experiments using PFA+Sap (Figure 2) demonstrated that the number of post-fixation wash steps significantly impacted the retention of PE by ASCs. However, it is unknown if this phenomenon is buffer specific or could be observed using alternative buffer sets. To test this, we examined the effects of centrifugation using the eBioscience Foxp3/Transcription Factor Staining Buffer Set (Figure 3A). We chose this buffer set as it has been previously used in the context of ICFC and demonstrated PEretention in day 3 cultures from LPS-stimulated B cells (Bohacova et al., 2021). Notably, this timepoint would be expected to contain a significant proportion of ASCs.

When we varied the number of post-fixation washes with Foxp3 Buffer 2 (B2) (Figure 3A, red), we again observed differences in retention. Not surprisingly, BCs showed a reduction in background PE staining which was most evident in the step from 1 to 2 washes (Figures 3B-C). Unlike with PFA+Sap, increasing the number of Foxp3 B2 washes did not dramatically enhance ASC retention of PE (Figures 3B-C). Rather, the use of multiple washes lowered the overall PE gMFI in ASCs (Figures 3B-C) as demonstrated by a left shift of the primary peak of fluorescence intensity. However, the use of 2 or 3 washes induced a separate artifact of PE retention as indicated by the "tails" present in the rIgG2a-PE histograms of multi-washed ASCs (Figure 3B). Overall, we did not observe major deviation in the ASC / BC PE gMFI ratio when different numbers of washes were compared (Figure 3C). To further characterize this phenomenon, we repeated experiments from Figure 2 in which we varied postfixation wash number and RCF. Similar to PFA+Sap, altering RCF did not change PE retention by 
bioRxiv preprint doi: https://doi.org/10.1101/2022.01.10.475671; this version posted January 11, 2022. The copyright holder for this preprint (which was not certified by peer review) is the author/funder. All rights reserved. No reuse allowed without permission.

Antibody-secreting cell intracellular flow

ASCs (Figures 3E-G). While the artifacts induced by number of washes were specific to buffer sets, they shared the common theme of modulation by the number of post-fixation washes.

\subsection{Fixation and permeabilization method does not differentially impact the analysis of live versus dead antibody-secreting cells}

The above experiments indicated that different fixation and permeabilization methodologies induced distinct types of PE retention artifacts in ASCs. Since both protocols are known to impact cellular morphology in their own unique fashion, it is possible that this led to false comparison of ASCs between the 2 methods. That is, a particular method may have included a significant proportion of dead ASCs which may have skewed the results. To exclude this possibility, we repeated the single postfixation wash PFA+Sap and Foxp3 ICFC protocols with the inclusion of a fixable Live-Dead stain (Figures 4). As expected, total ungated events demonstrated a clear positive population indicative of dead cells regardless of the buffer system used (Figures 4A-B). When using PFA+Sap, the percentages of gated BCs and ASCs that were Live-Dead ${ }^{+}$were $~ 1.8 \%$ and $1.0 \%$, respectively (Figures $4 \mathrm{~A}$ and 4C). Interestingly, the use of the Foxp3 buffer set increased the percentage of dead BCs that were analyzed to $\sim 17 \%$. However, only about $0.8 \%$ of ASCs analyzed were considered dead (Figures 4B C). Even though the Foxp3 buffer set increased the percentage of dead BCs that were gated, this did not impact PE gMFIs as total and dead BCs showed similar PE background when stained with rIgG2aPE $(0.2 \mu \mathrm{g})$ (Figure 4D). Overall, these data indicated that different fixation and permeabilization methods had little impact on the analysis of gated, viable ASCs.

\subsection{Performance of one post-fixation wash using the eBioscience Foxp3/Transcription Factor Staining Buffer Set allows for robust intracellular staining of antibody-secreting cells}

The above results indicated that a single post-fixation wash protocol using either PFA+Sap or the Foxp3 buffer set may be suitable for ICFC of ASCs when PE-conjugated Abs were present. However, the Foxp3 buffer set, usually in the context of 2 post-fixation washes, is believed to provide increased ICFC utility as it is designed to provide optimal staining of organelle-localized antigens including those in the nucleus (Law et al., 2009). To address these concepts, we compared the use of 1 or 2 postfixation washes with both buffer sets to detect Pro-IL-1 $\beta$ and TLR7 (Figures 5A-D).

Pro-IL-1 $\beta$ was chosen as the Immunological Genome Project (ImmGen, https://www.immgen.org) datasets have shown the $I l 1 b$ gene to be preferentially expressed in SPL ASCs, in particular PBs, when compared to total SPL BCs (Supplementary Figure 2A). Pro-IL-1 $\beta$ has also been detected in protein lysates from human peripheral blood CD19+ $\mathrm{B}$ cells (Lim et al., 2020). Finally, cleavage of Pro-IL-1 $\beta$ to its mature IL-1 $\beta$ form and subsequent secretion typically requires integration of multiple "danger" signals (Gurung et al., 2015). As a result, we hypothesized that Pro-IL-1 $\beta$ would accumulate and not be processed under homeostatic conditions thus facilitating its detection. TLR7 was selected as it predominantly localizes to the endosome (Kuznik et al., 2011) allowing for the comparison of cytoplasmic (i.e. Pro-IL-1 $\beta$ ) versus organelle-localized staining efficacy. Additionally, $\operatorname{Tl} 7$ has been shown to be robustly expressed in mouse SPL BCs and ASCs (ImmGen, Supplementary Figure 2B) as well as in human tonsillar counterparts (Dorner et al., 2009).

For these experiments, we further gated SPL BCs as CD19 ${ }^{+}$to confirm their identity (Supplementary Figure 2C). Fixable Live-Dead staining was also included in all samples to ensure analysis of viable cells. The use of 1 post-fixation wash (Figure 5A) allowed for clear detection of Pro-IL-1 $\beta$ with ASCs having an increased percentage of Pro-IL- $1 \mathrm{~b}^{+}$cells relative to BCs (Figure 5C). The use of the Foxp3 buffer set led to modestly increased detection of ASC Pro-IL-1 $\beta$ when compared to PFA+Sap (Figures 
bioRxiv preprint doi: https://doi.org/10.1101/2022.01.10.475671; this version posted January 11, 2022. The copyright holder for this preprint (which was not certified by peer review) is the author/funder. All rights reserved. No reuse allowed without permission. Antibody-secreting cell intracellular flow

292

293

294

295

296

297

298

299

300

301

302

303

304

305

306

307

308

309

310

311

312

313

314

315

316

317

318

319

320

321

322

323

324

325

326

327

328

329

330

331

332

333

334

335

336

337

338
5A and 5C). In contrast, the use of 2 post-fixation washes resulted in $\mathrm{PE} / \mathrm{Cy} 7$ retention that prohibited accurate quantification of Pro-IL-1 $\beta$ in ASCs (Figures 5A and 5C and Supplementary Figure 2D). Interestingly, detection of Pro-IL-1 $\beta$ was lost in 2 post-fixation wash SPL BCs regardless of buffer set (Figures 5A and 5C).

Unlike Pro-IL-1 $\beta$, TLR7 was minimally detectable when the 1 wash PFA+Sap protocol was utilized (Figure 5B). Conversely, the 1 wash Foxp3 protocol resulted in the detection of high amounts of TLR7 (Figures 5B and 5D). PFA+Sap in combination with 2 post-fixation washes showed an intermediate TLR7 staining in BCs when compared to results observed with a single post-fixation wash with PFA+Sap and Foxp3 buffers (Figures 5B and 5D). Respective to BCs, the 2 wash Foxp3 buffer protocol appeared to be equivalent to the 1 wash version as both displayed $\sim 56-62 \%$ average TLR7 positivity with similar gMFIs (Figures 5B and 5D and Supplementary Figure 2E). Examination of ASCs again demonstrated PE retention when 2 post-fixation washes were used in the context of $\mathrm{PFA}+$ Sap (Figure 5B). This was indicated by increased PE gMFIs in isotype control samples (Figure 5B and Supplementary Figure 2E). We also observed ASC retention of PE in 2 post-fixation wash Foxp3 buffer set samples (Figure 5B). Rather than a dramatic shift in gMFI, the retention observed resembled the previously mentioned "tail" pattern (Figure 5B) and resulted in an under estimation of the overall percentage of TLR7 $7^{+}$ASCs (Figure 5D). In general, both 1 post-fixation wash protocols suppressed PE/Cy7 and PE retention of ASCs for the protein targets shown here. However, the 1 postfixation wash Foxp3 buffer set protocol provided the most reproducible results and allowed for the detection of cytoplasmic as well as organelle-localized proteins.

\section{Discussion}

While it has been reported that ASCs non-specifically retain PE in the context of ICFC (Bohacova et al., 2021; Kim and Kim, 2013), our current study confirms and extends these findings to include $\mathrm{PE} / \mathrm{Cy} 7$. A key finding shown here is that the mere act of repetitive centrifugation post-fixation appears to induce the ASC retention of PE. As such, reduction in the number of post-fixation washes and centrifugation steps that occur before ICFC staining ameliorates this phenotype thus allowing for the utilization of extremely bright PE and PE/Cy7 fluorochromes in ASC ICFC.

Previous attempts (Bohacova et al., 2021; Kim and Kim, 2013) to eliminate ASC retention of PE with multiple types of commercial ICFC buffer sets have been unsuccessful. These have included the BD Biosciences CytoFix/Cytoperm buffer set (Kim and Kim, 2013) as well as Foxp3 buffer sets from BD Biosciences, BioLegend and eBioscience/Thermo Fisher Scientific (Bohacova et al., 2021). Interestingly, standard protocols for all of these buffer sets call for multiple centrifugation steps following initial cellular fixation. The only exception to this is the eBioscience Foxp3 buffer set which provides multiple ICFC protocols. One of these, Protocol B, uses a single mandatory centrifugation step post-fixation and was tested and shown to be "curative" in this study (Figures 3 and 5). Importantly, a single post-fixation wash also was sufficient to reduce PE retention in the context of PFA+Sap providing some flexibility in what buffers are utilized (Figures 3 and 5). This may be an important consideration as different antigens display altered sensitivities in regards to how fixation impacts their Ab-binding epitopes. In regard to the protein targets tested here, optimal staining of ASC intracellular proteins was observed while using the eBioscience Foxp3/Transcription Factor Staining Buffer Set rather than PFA+Sap (Figure 5). This was most obvious when 1 post-fixation wash was performed (Figure 5) and may simply be a result of the permeabilization agents that differ between protocols. Sap is a "weak" detergent which has been used to permeabilize fixed cells for ICFC; however, instances have been observed in which Sap does not effectively permeabilize certain types of membranes (Mercanti and Cosson, 2010). Under these circumstances, Triton X-100 has served as a 
bioRxiv preprint doi: https://doi.org/10.1101/2022.01.10.475671; this version posted January 11, 2022. The copyright holder for this preprint (which was not certified by peer review) is the author/funder. All rights reserved. No reuse allowed without permission. Antibody-secreting cell intracellular flow

339

340

341

342

343

344

345

346

347

348

349

350

351

352

353

354

355

356

357

358

359

360

361

362

363

364

365

366

367

368

369

370

371

372

373

374

375

376

377

378

379

380

381

382

383

384

385

386

387

more appropriate method as this "strong" detergent is commonly used for immunofluorescence of nuclear proteins (Spector, 2011). While the permeabilizing agent contained within the eBioscience Foxp3/Transcription Factor Staining Buffer Set used here is not explicitly stated, similar kits such as the Human FoxP3 Buffer Set (Catalog \# 560098) from BD Biosciences is known to contain methanol, a common reagent used to fix and permeabilize cells during ICFC (Levitt and King, 1987). Relatedly, we did observe differences in the type of PE retention when PFA+Sap and Foxp3 buffer sets were compared. We speculate that this may simply be a consequence of how the different buffer sets interact with cells. For example, PFA fixation leads to protein-protein crosslinks that also preserve overall cell structure. In contrast, methanol is an organic solvent which precipitates proteins through dehydration resulting in distortion of cellular morphology. This is readily observed when forward and side scatter properties of cells treated with these reagents are examined on a flow cytometer. However, the idea remains to be tested. Lastly, we did find some variance between isotypes in the magnitude of PE and $\mathrm{PE} / \mathrm{Cy} 7$ retention (Figure 1 and Figure 3 versus Figure 5). While we do not currently know the cause of this phenomenon, it may be related to differences in constant domain structure between antibody isotypes (Schroeder and Cavacini, 2010). For example, differences in lysine amino acid number may directly impact efficiency of fluorochrome conjugation (Nanna et al., 2017). In this sense, increased lysine residues within a particular isotype could lead to a higher ratio of fluorochrome conjugation and thus higher retention of PE.

An obvious question becomes why do ASCs exhibit PE retention and by extension, why does centrifugation augment this retention phenotype? While our study does not directly address this, a possibility may be related to the major function of ASCs which is the production of Abs. Of note, Abs are heavily glycosylated (Irvine and Alter, 2020) and various compounds exist that bind carbohydrates (Sun et al., 2016) facilitating their detection independent of specific antibody:antigen interactions. Therefore, it is tempting to speculate that the high abundance of intracellular immunoglobulins combined with repetitive centrifugation can induce PE retention through incidental damage to cellular glycoproteins resulting in exposure of PE-interacting surfaces or structures. Alternatively, ASCs possess an expanded endoplasmic reticulum (ER) and Golgi network which may also suffer from the same post-centrifugation consequences hypothesized for Abs. Along these lines, it would be of interest to investigate PE retention in other cells which possess an expanded ER compartment such as plasmacytoid dendritic cells (pDCs) (Colonna et al., 2004). Would the deletion of Xbpl which leads to loss of the expanded ER network in ASCs (Taubenheim et al., 2012) and pDCs (Iwakoshi et al., 2007) result in the loss of PE retention?

Regardless of causation, the ability to ameliorate PE retention, as shown here, now facilitates the usage of PE- and PE/Cy7- conjugated Abs in assessing intracellular protein expression by ASCs. This is relevant to stand alone analysis of ASCs as well as comparison to other cell types such as naive or activated BCs. This is a critical point as BC to ASC differentiation has been correlated with acquisition of selected cytokine expression (Shi et al., 2015; Suzuki-Yamazaki et al., 2017) and could theoretically serve as a key diagnostic tool in the right context (Fink, 2012). As such, reducing any potential for a false positive is critical (Savasan et al., 2018). To this end, FMOs and isotype control Abs have both been utilized in the field of flow cytometry and hotly debated in regards to what the "correct" strategy is. We would suggest that much like anything else, this depends on context. For ICFC of ASCs, the use of PE- and PE/Cy7-conjugated isotype control Abs is absolutely essential in identifying a retention phenotype (Figure 1) (Bohacova et al., 2021; Kim and Kim, 2013) that would have been misinterpreted for positive staining if only FMO samples and those stained with target specific Abs were assessed.

Finally, we provide biological insight at the protein level into the evolution of ASCs and their potential to interact with their surrounding environment. RNA sequencing of mouse bone marrow plasma cells 
bioRxiv preprint doi: https://doi.org/10.1101/2022.01.10.475671; this version posted January 11,2022 . The copyright holder for this preprint (which was not certified by peer review) is the author/funder. All rights reserved. No reuse allowed without permission. Antibody-secreting cell intracellular flow

\section{$411 \quad$ Funding}

412 This study was supported by startup funds from the Western Michigan University Homer Stryker M.D.

413 School of Medicine.

\section{Acknowledgments}

415 Flow cytometry was performed at the WMed Flow Cytometry and Imaging Core which is managed by

416 Michael Clemente.

(Pioli et al., 2019) as well as quantitative polymerase chain reaction of human peripheral blood plasmablasts and tonsillar plasma cells (Dorner et al., 2009) has demonstrated expression of $\mathrm{Tlr} 7$ at the gene level. We show here that a portion of SPL ASCs express TLR7 (Figure 5). Given the role of this protein during viral responses (Lester and Li, 2014), it will be interesting to see how ASC expression of TLR7 changes during infection and whether or not this contributes to the functionality of these cells. Furthermore, we show increased Pro-IL-1 $\beta$ expression in SPL ASCs compared to their upstream BC counterparts (Figure 5). This coincides with RNA sequencing data available in the ImmGen database (http://rstats.immgen.org/Skyline/skyline.html) which illustrates enriched expression of $1 l 1 b$ transcripts in SPL plasmablasts relative total BCs (Supplementary Figure 2A).

In summary, we have identified a key contributing factor to the ASC retention of PE molecules during ICFC. It should be noted that this and other studies (Bohacova et al., 2021; Kim and Kim, 2013) regarding ASC retention of PE have focused on murine cells. Human ASCs are ultra-structurally similar to those from mice (e.g. expanded ER network); however, it is currently unknown if human ASCs suffer from the same PE retention. Regardless, we provide a framework to not only determine the existence of PE retention in human ASCs and other cell types (e.g. pDCs) but to also ameliorate its impact on ICFC staining.

\section{Disclosure}

The authors declare no commercial or financial relationships that could be construed as a potential conflict of interest.

\section{Author Contributions}

KATP and PDP conceptualized the study. PR, MC, MK and KATP performed experiments. KATP and PDP analyzed data. PDP wrote the manuscript and all authors approved the final version. 
bioRxiv preprint doi: https://doi.org/10.1101/2022.01.10.475671; this version posted January 11,2022 . The copyright holder for this preprint (which was not certified by peer review) is the author/funder. All rights reserved. No reuse allowed without permission. Antibody-secreting cell intracellular flow

\section{References}

419 Amanna, I.J., Carlson, N.E., and Slifka, M.K. (2007). Duration of humoral immunity to common viral and vaccine antigens. The New England journal of medicine 357, 1903-1915. phycoerythrin and allophycocyanin for fluorescence resonance energy transfer analyzed by flow cytometry: advantages and limitations. Cytometry 48, 97-105.

424 Bohacova, P., Kossl, J., Hajkova, M., Hermankova, B., Holan, V., and Javorkova, E. (2021). Difference between mitogen-stimulated B and T cells in nonspecific binding of R-phycoerythrinconjugated antibodies. Journal of immunological methods 493, 113013.

427 Chavele, K.M., Merry, E., and Ehrenstein, M.R. (2015). Cutting edge: circulating plasmablasts induce the differentiation of human T follicular helper cells via IL-6 production. Journal of immunology 194, 2482-2485.

430 Chin, S.S., Chorro, L., Chan, J., and Lauvau, G. (2019). Splenic Innate B1 B Cell Plasmablasts Produce Sustained Granulocyte-Macrophage Colony-Stimulating Factor and Interleukin-3 Cytokines during Murine Malaria Infections. Infect Immun 87.

433 Colonna, M., Trinchieri, G., and Liu, Y.J. (2004). Plasmacytoid dendritic cells in immunity. Nature 434 immunology 5, 1219-1226.

435 Dorner, M., Brandt, S., Tinguely, M., Zucol, F., Bourquin, J.P., Zauner, L., Berger, C., Bernasconi, M., Speck, R.F., and Nadal, D. (2009). Plasma cell toll-like receptor (TLR) expression differs from that of B cells, and plasma cell TLR triggering enhances immunoglobulin production. Immunology $128,573-579$.

Fairfax, K.A., Kallies, A., Nutt, S.L., and Tarlinton, D.M. (2008). Plasma cell development: from Bcell subsets to long-term survival niches. Seminars in immunology 20, 49-58.

441 Fink, K. (2012). Origin and Function of Circulating Plasmablasts during Acute Viral Infections. 442 Frontiers in immunology 3, 78.

443 Gaudette, B.T., and Allman, D. (2021). Biochemical coordination of plasma cell genesis.

444 Immunological reviews 303, 52-61.

445 Gurung, P., Li, B., Subbarao Malireddi, R.K., Lamkanfi, M., Geiger, T.L., and Kanneganti, T.D. (2015). Chronic TLR Stimulation Controls NLRP3 Inflammasome Activation through IL-10 Mediated Regulation of NLRP3 Expression and Caspase-8 Activation. Scientific reports 5, 14488. Irvine, E.B., and Alter, G. (2020). Understanding the role of antibody glycosylation through the lens of severe viral and bacterial diseases. Glycobiology 30, 241-253. for the development and survival of dendritic cells. The Journal of experimental medicine 204, 22672275.

453 Katkov, II, and Mazur, P. (1999). Factors affecting yield and survival of cells when suspensions are subjected to centrifugation. Influence of centrifugal acceleration, time of centrifugation, and length of the suspension column in quasi-homogeneous centrifugal fields. Cell Biochem Biophys 31, 231-245. 
bioRxiv preprint doi: https://doi.org/10.1101/2022.01.10.475671; this version posted January 11, 2022. The copyright holder for this preprint (which was not certified by peer review) is the author/funder. All rights reserved. No reuse allowed without permission. Antibody-secreting cell intracellular flow

459

460

461

462

463

464

465

466

467

468

469

470

471

472

473

474

475

476

477

478

479

480

481

482

483

484

485

486

487

488

489

490

491

492

493

494

495

496

497

498

499
Kim, M.S., and Kim, T.S. (2013). R-phycoerythrin-conjugated antibodies are inappropriate for intracellular staining of murine plasma cells. Cytometry. Part A : the journal of the International Society for Analytical Cytology 83, 452-460.

Kuznik, A., Bencina, M., Svajger, U., Jeras, M., Rozman, B., and Jerala, R. (2011). Mechanism of endosomal TLR inhibition by antimalarial drugs and imidazoquinolines. Journal of immunology 186 , 4794-4804.

Landsverk, O.J., Snir, O., Casado, R.B., Richter, L., Mold, J.E., Reu, P., Horneland, R., Paulsen, V., Yaqub, S., Aandahl, E.M., et al. (2017). Antibody-secreting plasma cells persist for decades in human intestine. The Journal of experimental medicine 214, 309-317.

Law, J.P., Hirschkorn, D.F., Owen, R.E., Biswas, H.H., Norris, P.J., and Lanteri, M.C. (2009). The importance of Foxp3 antibody and fixation/permeabilization buffer combinations in identifying CD4+CD25+Foxp3+ regulatory T cells. Cytometry. Part A : the journal of the International Society for Analytical Cytology 75, 1040-1050.

Lester, S.N., and Li, K. (2014). Toll-like receptors in antiviral innate immunity. J Mol Biol 426, 1246-1264.

Levitt, D., and King, M. (1987). Methanol fixation permits flow cytometric analysis of immunofluorescent stained intracellular antigens. Journal of immunological methods 96, 233-237.

Lim, K.H., Chen, L.C., Hsu, K., Chang, C.C., Chang, C.Y., Kao, C.W., Chang, Y.F., Chang, M.C., and Chen, C.G. (2020). BAFF-driven NLRP3 inflammasome activation in B cells. Cell death \& disease 11,820 .

Lino, A.C., Dang, V.D., Lampropoulou, V., Welle, A., Joedicke, J., Pohar, J., Simon, Q., Thalmensi, J., Baures, A., Fluhler, V., et al. (2018). LAG-3 Inhibitory Receptor Expression Identifies Immunosuppressive Natural Regulatory Plasma Cells. Immunity 49, 120-133 e129.

Ma, K., Wang, X., Shi, X., Lin, X., Xiao, F., Ma, X., Liu, D., and Lu, L. (2020). The expanding functional diversity of plasma cells in immunity and inflammation. Cell Mol Immunol 17, 421-422.

Manakkat Vijay, G.K., and Singh, H. (2021). Cell fate dynamics and genomic programming of plasma cell precursors. Immunological reviews 303, 62-71.

Manz, R.A., Lohning, M., Cassese, G., Thiel, A., and Radbruch, A. (1998). Survival of long-lived plasma cells is independent of antigen. International immunology 10, 1703-1711.

Matsuda, Y., Fujii, T., Suzuki, T., Yamahatsu, K., Kawahara, K., Teduka, K., Kawamoto, Y., Yamamoto, T., Ishiwata, T., and Naito, Z. (2011). Comparison of fixation methods for preservation of morphology, RNAs, and proteins from paraffin-embedded human cancer cell-implanted mouse models. J Histochem Cytochem 59, 68-75.

Matsumoto, M., Baba, A., Yokota, T., Nishikawa, H., Ohkawa, Y., Kayama, H., Kallies, A., Nutt, S.L., Sakaguchi, S., Takeda, K., et al. (2014). Interleukin-10-producing plasmablasts exert regulatory function in autoimmune inflammation. Immunity 41, 1040-1051.

McGettigan, S.E., and Debes, G.F. (2021). Immunoregulation by antibody secreting cells in inflammation, infection, and cancer. Immunological reviews.

Meng, L., Almeida, L.N., Clauder, A.K., Lindemann, T., Luther, J., Link, C., Hofmann, K., Kulkarni, U., Wong, D.M., David, J.P., and Manz, R.A. (2019). Bone Marrow Plasma Cells Modulate Local Myeloid-Lineage Differentiation via IL-10. Frontiers in immunology 10, 1183. 
bioRxiv preprint doi: https://doi.org/10.1101/2022.01.10.475671; this version posted January 11, 2022. The copyright holder for this preprint (which was not certified by peer review) is the author/funder. All rights reserved. No reuse allowed without permission.

Antibody-secreting cell intracellular flow

500

501

502

503

504

505

506

507

508

509

510

511

512

513

514

515

516

517

518

519

520

521

522

523

524

525

526

527

528

529

530

531

532

533

534

535

536

537

538

539

540

541

Mercanti, V., and Cosson, P. (2010). Resistance of Dictyostelium discoideum membranes to saponin permeabilization. BMC Res Notes 3, 120.

Nanna, A.R., Li, X., Walseng, E., Pedzisa, L., Goydel, R.S., Hymel, D., Burke, T.R., Jr., Roush, W.R., and Rader, C. (2017). Harnessing a catalytic lysine residue for the one-step preparation of homogeneous antibody-drug conjugates. Nature communications 8,1112 .

Nutt, S.L., Hodgkin, P.D., Tarlinton, D.M., and Corcoran, L.M. (2015). The generation of antibodysecreting plasma cells. Nature reviews. Immunology 15, 160-171.

Pioli, P.D. (2019). Plasma Cells, the Next Generation: Beyond Antibody Secretion. Frontiers in immunology 10, 2768.

Pioli, P.D., Casero, D., Montecino-Rodriguez, E., Morrison, S.L., and Dorshkind, K. (2019). Plasma Cells Are Obligate Effectors of Enhanced Myelopoiesis in Aging Bone Marrow. Immunity.

Rauch, P.J., Chudnovskiy, A., Robbins, C.S., Weber, G.F., Etzrodt, M., Hilgendorf, I., Tiglao, E., Figueiredo, J.L., Iwamoto, Y., Theurl, I., et al. (2012). Innate response activator B cells protect against microbial sepsis. Science 335, 597-601.

Ribatti, D. (2017). The discovery of plasma cells: An historical note. Immunology letters 188, 64-67.

Rojas, O.L., Probstel, A.K., Porfilio, E.A., Wang, A.A., Charabati, M., Sun, T., Lee, D.S.W., Galicia, G., Ramaglia, V., Ward, L.A., et al. (2019). Recirculating Intestinal IgA-Producing Cells Regulate Neuroinflammation via IL-10. Cell 177, 492-493.

Savasan, S., Buck, S., Gadgeel, M., and Gabali, A. (2018). Flow cytometric false myeloperoxidasepositive childhood B-lineage acute lymphoblastic leukemia. Cytometry B Clin Cytom 94, 477-483.

Schroeder, H.W., Jr., and Cavacini, L. (2010). Structure and function of immunoglobulins. The Journal of allergy and clinical immunology 125, S41-52.

Shaffer, A.L., Shapiro-Shelef, M., Iwakoshi, N.N., Lee, A.H., Qian, S.B., Zhao, H., Yu, X., Yang, L., Tan, B.K., Rosenwald, A., et al. (2004). XBP1, downstream of Blimp-1, expands the secretory apparatus and other organelles, and increases protein synthesis in plasma cell differentiation. Immunity 21, 81-93.

Shen, P., Roch, T., Lampropoulou, V., O'Connor, R.A., Stervbo, U., Hilgenberg, E., Ries, S., Dang, V.D., Jaimes, Y., Daridon, C., et al. (2014). IL-35-producing B cells are critical regulators of immunity during autoimmune and infectious diseases. Nature 507, 366-370.

Shi, W., Liao, Y., Willis, S.N., Taubenheim, N., Inouye, M., Tarlinton, D.M., Smyth, G.K., Hodgkin, P.D., Nutt, S.L., and Corcoran, L.M. (2015). Transcriptional profiling of mouse B cell terminal differentiation defines a signature for antibody-secreting plasma cells. Nature immunology 16, 663673.

Slifka, M.K., Antia, R., Whitmire, J.K., and Ahmed, R. (1998). Humoral immunity due to long-lived plasma cells. Immunity 8, 363-372.

Spector, D.L. (2011). Immunofluorescence localization of nuclear proteins. Cold Spring Harb Protoc 2011, 1276-1280.

Sun, X., Zhai, W., Fossey, J.S., and James, T.D. (2016). Boronic acids for fluorescence imaging of carbohydrates. Chem Commun (Camb) 52, 3456-3469.

Suzuki-Yamazaki, N., Yanobu-Takanashi, R., Okamura, T., and Takaki, S. (2017). IL-10 production in murine $\operatorname{IgM}(+) \mathrm{CD} 138$ (hi) cells is driven by Blimp-1 and downregulated in class-switched cells. European journal of immunology 47, 493-503. 


\section{Antibody-secreting cell intracellular flow}

542 Taubenheim, N., Tarlinton, D.M., Crawford, S., Corcoran, L.M., Hodgkin, P.D., and Nutt, S.L.

543 (2012). High rate of antibody secretion is not integral to plasma cell differentiation as revealed by

544 XBP-1 deficiency. Journal of immunology 189, 3328-3338.

545 Weber, G.F., Chousterman, B.G., Hilgendorf, I., Robbins, C.S., Theurl, I., Gerhardt, L.M., Iwamoto, 546 Y., Quach, T.D., Ali, M., Chen, J.W., et al. (2014). Pleural innate response activator B cells protect 547 against pneumonia via a GM-CSF-IgM axis. The Journal of experimental medicine 211, 1243-1256.

548 Zhu, H., Bhatt, B., Sivaprakasam, S., Cai, Y., Liu, S., Kodeboyina, S.K., Patel, N., Savage, N.M.,

549 Sharma, A., Kaufman, R.J., et al. (2019). Ufbp1 promotes plasma cell development and ER

550 expansion by modulating distinct branches of UPR. Nature communications 10, 1084.

551

552 
bioRxiv preprint doi: https://doi.org/10.1101/2022.01.10.475671; this version posted January 11, 2022. The copyright holder for this preprint (which was not certified by peer review) is the author/funder. All rights reserved. No reuse allowed without permission.

Antibody-secreting cell intracellular flow

Figure Legends

554

Figure 1. ASCs non-specifically retain PE- and PE/Cy7-conjugated Abs. (A) Representative flow cytometry plots demonstrating gating of SPL B220 ${ }^{+}$CD138- BCs and B220 ${ }^{+/-}$CD $138^{\mathrm{HI}} \mathrm{CD}^{-}{ }^{-}$. $^{-} \mathrm{IgD}^{-}$ ASCs. Total ASCs were further subdivided into B220 ${ }^{+} \mathrm{PB}$ and $\mathrm{B} 220^{-} \mathrm{PC}$. Cells are pre-gated on total singlets. CD138 versus CD90.2+IgD staining of total singlets in shown for reference. (B-D) Flow cytometry overlay histograms showing fluorescence intensity for (B) APC, (C) PE and (D) PE/Cy7. FMO and isotype control $\mathrm{Ab}(0.04$ and $0.020 \mu \mathrm{g})$ stains are shown for SPL BCs, total ASCs, PBs and PCs. Data are representative of 3 individual experiments and gMFIs are summarized in Supplementary Fig. 1.

Figure 2. The number of post-fixation washes modulates ASC retention of PE- and PE/Cy7conjugated Abs. (A) Schematic depicting PFA+Sap staining protocol. (B) Flow cytometry overlay histograms showing rIgG2a-PE fluorescence intensity for SPL BCs and ASCs using 1, 2 or 3 poststain Sap washes. (C) rIgG2a-PE $(0.20 \mu \mathrm{g})$ gMFIs of SPL BCs and ASCs washed 1, 2 or 3 times with Sap following staining. (D) Ratio of SPL ASC / BC rIgG2a-PE (0.20 $\mu \mathrm{g})$ gMFIs from cells washed 1, 2 or 3 times with Sap following staining. Horizontal dashed line represents a ratio of 1. (E) Flow cytometry overlay histograms showing rIgG2a-PE fluorescence intensity for SPL BCs and ASCs using $\mathrm{Sap} / \mathrm{Sap}, \mathrm{BSA} / \mathrm{Sap}$ or PBS/Sap 2-step washes post-fixation. (F) rIgG2a-PE (0.20 $\mu \mathrm{g}) \mathrm{gMFIs}$ of SPL BCs and ASCs washed with Sap/Sap (S/S), BSA/Sap (B/S) or PBS/Sap (P/S). (G) Ratio of SPL ASC / BC rIgG2a-PE $(0.20 \mu \mathrm{g})$ gMFIs from cells washed with $\mathrm{S} / \mathrm{S}, \mathrm{B} / \mathrm{S}$ or $\mathrm{P} / \mathrm{S}$. Horizontal dashed line represents a ratio of 1 . (H) Flow cytometry overlay histograms showing rIgG2a-PE fluorescence intensity for SPL BCs and ASCs using 1, 2 or 3 post-fixation Sap washes. (I) rIgG2a-PE $(0.20 \mu \mathrm{g})$ gMFIs of SPL BCs and ASCs washed 1, 2 or 3 times with Sap following fixation. (J) Ratio of SPL ASC / BC rIgG2a-PE $(0.20 \mu \mathrm{g})$ gMFIs from cells washed 1, 2 or 3 times with Sap following fixation. Horizontal dashed line represents a ratio of 1 . (K) Flow cytometry overlay histograms showing rIgG2aPE fluorescence intensity for SPL BCs and ASCs using 1 or 2 post-fixation Sap washes at 600g or 300g. (L) rIgG2a-PE $(0.20 \mu \mathrm{g})$ gMFIs of SPL BCs and ASCs washed 1 or 2 times at $600 \mathrm{~g}$ or $300 \mathrm{~g}$ with Sap following fixation. (M) Ratio of SPL ASC / BC rIgG2a-PE (0.20 $\mu \mathrm{g})$ gMFIs from cells washed 1 or 2 times at $600 \mathrm{~g}$ or $300 \mathrm{~g}$ with Sap following fixation. Horizontal dashed line represents a ratio of 1. (B-D, H-J) Data derived from 4 separate experiments. (E-G, K-M) Data derived from 2-4 separate experiments. (C-D, F-G, I-J, L-M) Symbols represent individual mice. Horizontal lines represent mean $\pm \mathrm{SEM}$.

584 Figure 3. The number of post-fixation washes modulates ASC retention of PE-conjugated Abs 585 when using the eBioscience Foxp3/Transcription Factor Staining Buffer Set. (A) Schematic depicting Foxp3 staining protocol. (B) Flow cytometry overlay histograms showing rIgG2a-PE fluorescence intensity for SPL BCs and ASCs using 1, 2 or 3 post-fixation Foxp3 B2 washes. (C) rIgG2a-PE $(0.20 \mu \mathrm{g}) \mathrm{gMFIs}$ of SPL BCs and ASCs washed 1, 2 or 3 times with Foxp3 B2 following fixation. (D) Ratio of SPL ASC / BC rIgG2a-PE $(0.20 \mu \mathrm{g}) \mathrm{gMFIs}$ from cells washed 1, 2 or 3 times with Foxp3 B2 following fixation. Horizontal dashed line represents a ratio of 1. (E) Flow cytometry overlay histograms showing rIgG2a-PE fluorescence intensity for SPL BCs and ASCs using 1 or 2 post-fixation Foxp3 B2 washes at $600 \mathrm{~g}$ or $300 \mathrm{~g}$. (F) rIgG2a-PE $(0.20 \mu \mathrm{g}) \mathrm{gMFIs}$ of SPL BCs and ASCs washed 1 or 2 times at $600 \mathrm{~g}$ or $300 \mathrm{~g}$ with Foxp3 B2 following fixation. (G) Ratio of SPL ASC / BC rIgG2a-PE $(0.20 \mu \mathrm{g})$ gMFIs from cells washed 1 or 2 times at $600 \mathrm{~g}$ or $300 \mathrm{~g}$ with Foxp3 B2 following fixation. Horizontal dashed line represents a ratio of 1. (B-G) Data derived from 2 separate experiments. (C-D, F-G) Symbols represent individual mice. Horizontal lines represent mean \pm SEM. 
bioRxiv preprint doi: https://doi.org/10.1101/2022.01.10.475671; this version posted January 11, 2022. The copyright holder for this preprint (which was not certified by peer review) is the author/funder. All rights reserved. No reuse allowed without permission.

Antibody-secreting cell intracellular flow

597

598

599

600

601

602

603

604

605

606

607

608

609

610

611

612

613

614

615

616

617

618

619

620

621

622

623

624

625

626

627

628

629

630

631

632

633

634

635

636

637
Figure 4: Fixation and permeabilization method does not differentially impact the analysis of live versus dead ASCs. (A-B) Representative flow cytometry plots demonstrating Live-Dead staining of total SPL events as well as gated BCs and ASCs. Samples were processed using (A) PFA+Sap or the (B) Foxp3 buffer set. Dead cells are gated and percentages of Live-Dead ${ }^{+}$cells are indicated in red. (C) Percentages of Live-Dead ${ }^{+}$cells within total SPL events, BCs and ASCs. Symbols represent individual mice. Horizontal lines represent mean \pm SEM. (D) Flow cytometry overlay histograms showing rIgG2a-PE fluorescence intensity for total and dead SPL BCs using the Foxp3 buffer set. (AD) Data derived from 2 separate experiments.

Figure 5. Performance of one post-fixation wash using the eBioscience Foxp3/Transcription Factor Staining Buffer Set allows for robust intracellular staining of ASC proteins. (A) Flow cytometry overlay histograms showing rIgG1-PE/Cy7 isotype control and Pro-IL-1 $\beta-\mathrm{PE} / \mathrm{Cy} 7$ fluorescence intensity for SPL CD19+ BCs, ASCs, PBs and PCs with 1 or 2 post-fixation washes using either PFA+Sap or Foxp3 protocols. (B) Flow cytometry overlay histograms showing mouse IgG1 (mIgG1)-PE isotype control and TLR7-PE fluorescence intensity for SPL CD19+ BCs, ASCs, PBs and PCs with 1 or 2 post-fixation washes using either PFA+Sap or Foxp3 protocols. (C) Percentages of Pro-IL-1 $\beta^{+}$cells within CD19+ $9^{+}$Bs and ASCs. Symbols represent individual mice. Horizontal lines represent mean \pm SEM. (D) Percentages of TLR7 ${ }^{+}$cells within CD19 ${ }^{+}$BCs and ASCs. Symbols represent individual mice. Horizontal lines represent mean \pm SEM. (A-B) Red vertical lines added to histograms to depict positive staining for Pro-IL-1 $\beta$ and TLR7. (A-D) Data representative of 3 individual experiments.

Supplementary Figure 1: PE- and PE/Cy7-conjugated Abs are retained by ASCs in a concentration dependent manner. Flow cytometry-derived geometric mean fluorescence intensities (gMFIs) for various isotype control Abs conjugated to (A-B) APC, (C-D) PE and (E-F) PE/Cy7. (A, C, E) Data shown for $\mathrm{B} 220^{+} \mathrm{CD} 138^{-} \mathrm{BCs}$ and $\mathrm{B} 220^{+/} \mathrm{CD} 138^{\mathrm{HI}} \mathrm{CD} 90.2^{-} \mathrm{IgD}^{-} \mathrm{ASCs}$ using 0.04 and $0.20 \mu \mathrm{g}$ per $\mathrm{Ab}$ as well as FMO controls. (B, D, F) Data shown for $\mathrm{B} 220^{+} \mathrm{CD} 138^{\mathrm{HI}} \mathrm{CD} 90.2^{-} \mathrm{IgD}^{-} \mathrm{PBs}$ and $\mathrm{B} 220^{-} \mathrm{CD} 138^{\mathrm{HI}} \mathrm{CD}^{-}{ }^{-} 2^{-} \mathrm{IgD}^{-} \mathrm{PCs}$ using 0.04 and $0.20 \mu \mathrm{g}$ per $\mathrm{Ab}$ as well as FMO controls. (A-F) Symbols represent individual mice from 3 separate experiments. Horizontal lines represent mean \pm SEM.

Supplementary Figure 2: One post-fixation wash using the eBioscience Foxp3/Transcription Factor Staining Buffer Set allows for robust intracellular staining of ASC proteins. (A) ImmGen $I l 1 b$ expression data for SPL BCs, PBs and PCs. (B) ImmGen Tlr7 expression data for SPL BCs, PBs and PCs. (C) Representative flow cytometry plots demonstrating CD19 gating within the BC population compared to total singlets using either PFA+Sap or Foxp3 protocols. Red vertical lines added to histograms to depict positive staining for CD19. (D) Flow cytometry-derived gMFIs for PE/Cy7-conjugated isotype control and Pro-IL-1 $\beta$ Abs using 1 post-fixation wash and 2 post-fixation wash versions of the PFA+Sap $(\mathrm{P}+\mathrm{S})$ and Foxp3 protocols. (E) Flow cytometry-derived gMFIs for PE-conjugated isotype control and TLR7 Abs using 1 post-fixation wash and 2 post-fixation wash versions of the PFA+Sap $(\mathrm{P}+\mathrm{S})$ and Foxp3 protocols. (A-B) ImmGen data represent expression values normalized by DESeq2. Data were downloaded and replotted as is without further calculation. (D-E) Symbols represent individual mice from 3 separate experiments. Horizontal lines represent mean \pm SEM. 
Figure 1

A

Total Singlets

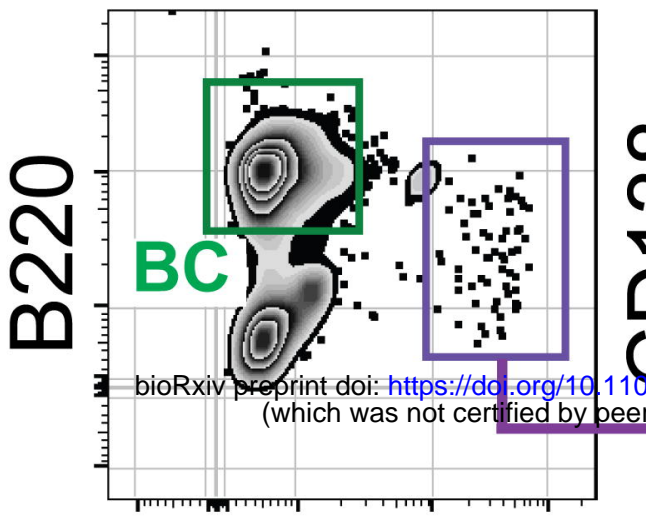

CD138

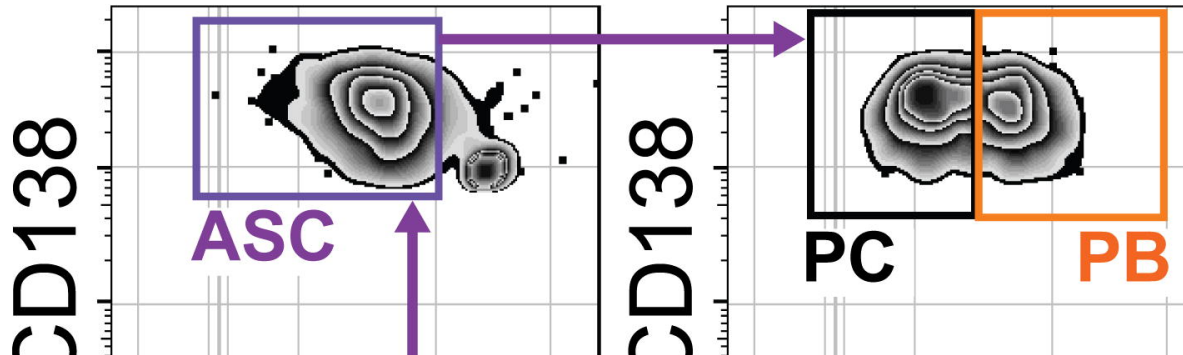

202. 01.10.475671; this version posted Jan uary-1, 22. The copyright holder for this preprin ) is the author/funder. All rights reserved.

CD90.2+lgD

B220

\section{Total Singlets}

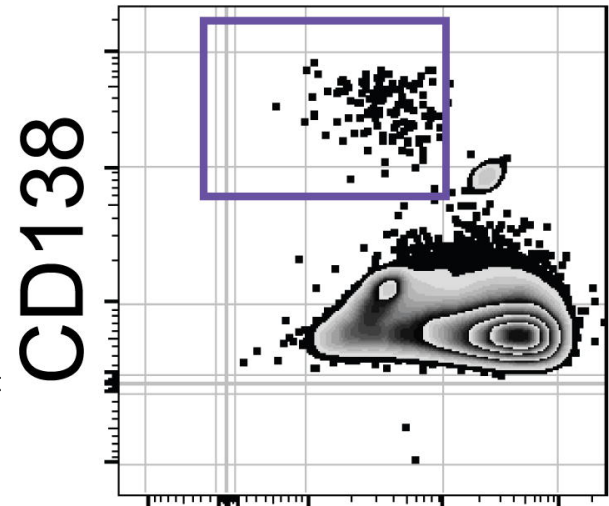

CD90.2+lgD
BC

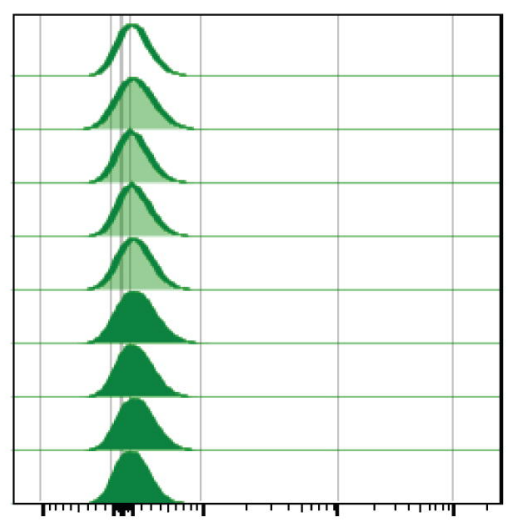

APC
ASC

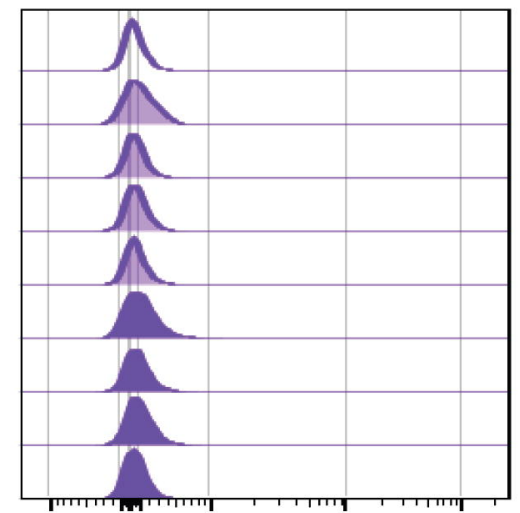

PB

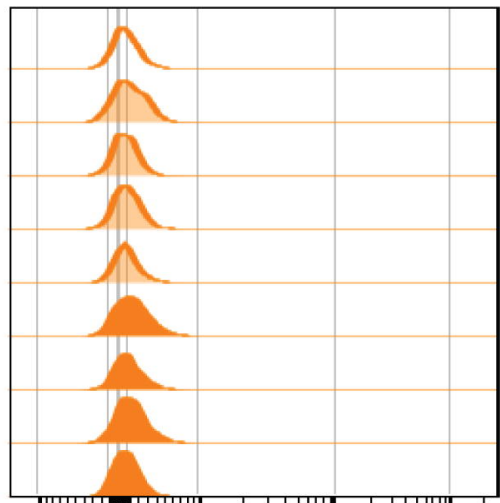

PC
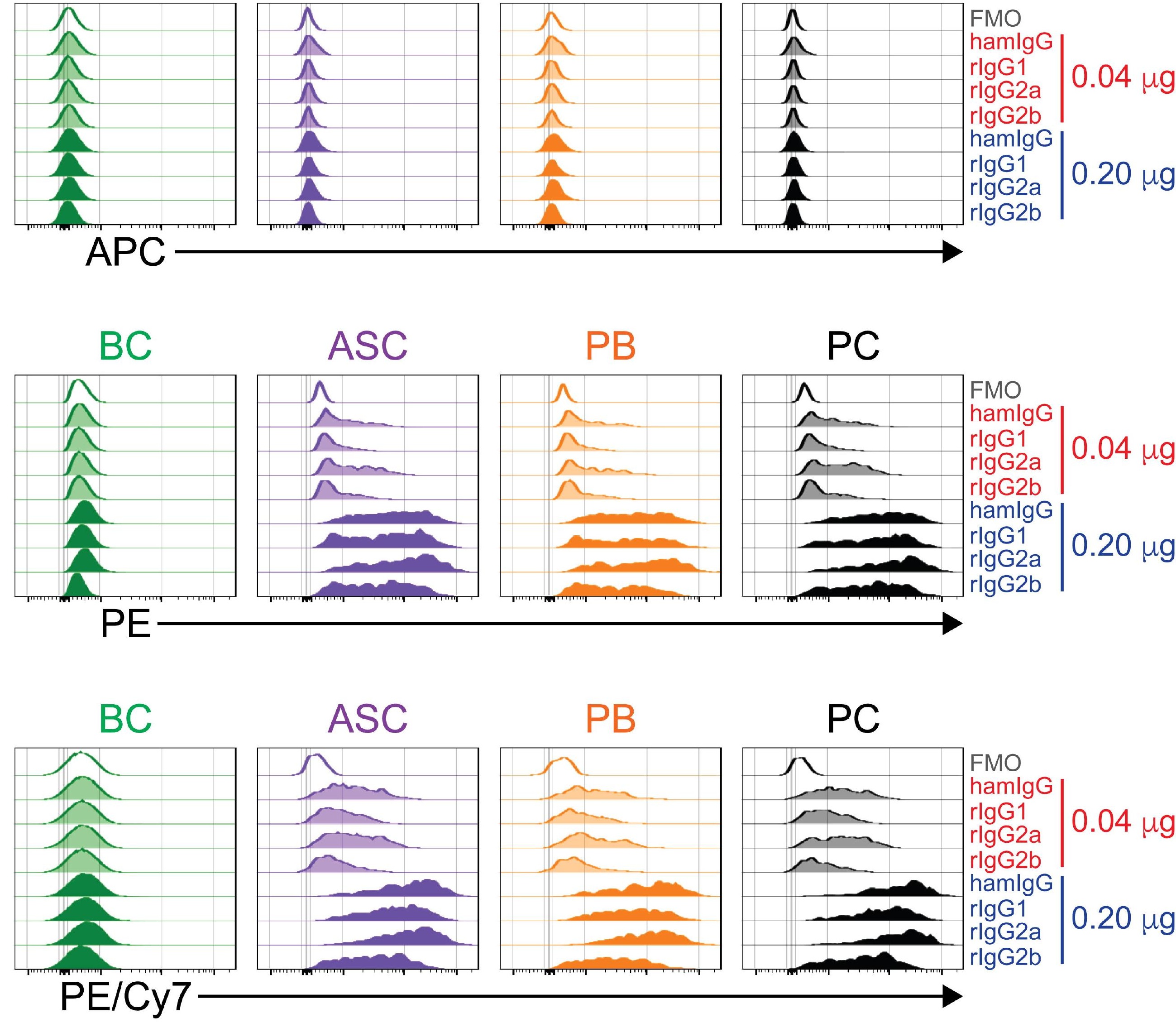


\section{Figure 3}

A

\section{Foxp3 Protocol}

1) Foxp3 $\longrightarrow$ 2) Wash $\longrightarrow$ 3) Decant $\& \longrightarrow$ 4) Decant $\& \longrightarrow$ 5) Wash $\longrightarrow$ 6) Decant $\& \longrightarrow$ 7) Analyze Buffer 1 w/ B2 Wash w/ $(B 1,1 \mathrm{~mL})$

$(2 \mathrm{~mL})$

B2 $(2 \mathrm{~mL})$ Block/Stain

w/ B2 Wash w/

$$
\text { B }
$$
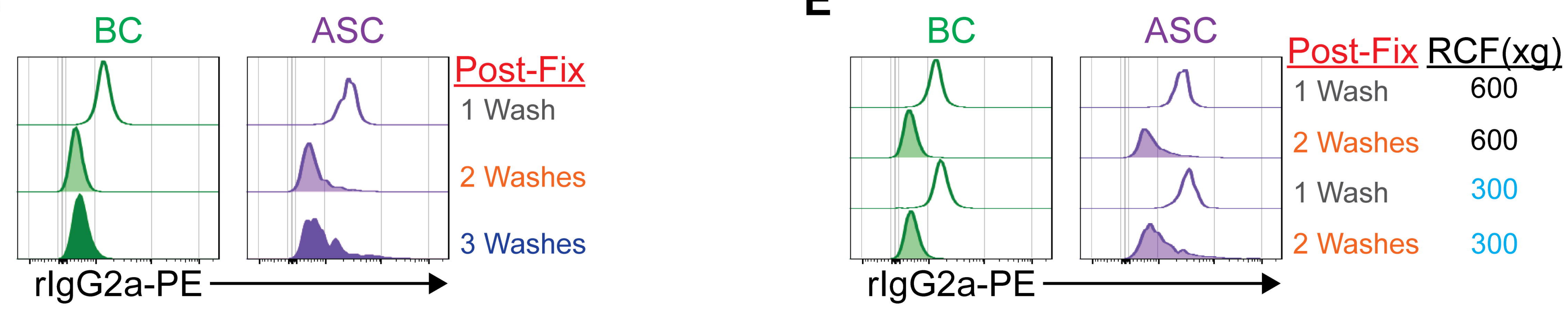

C

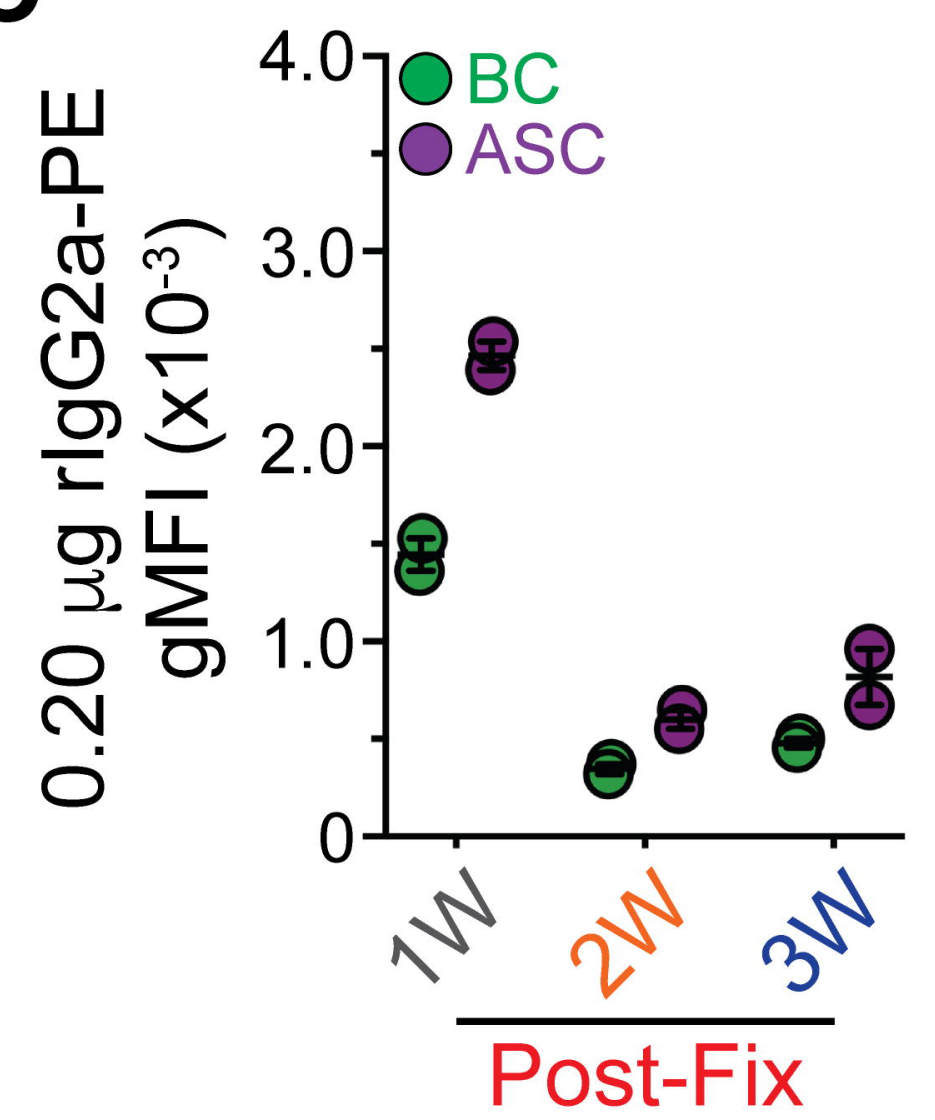

D

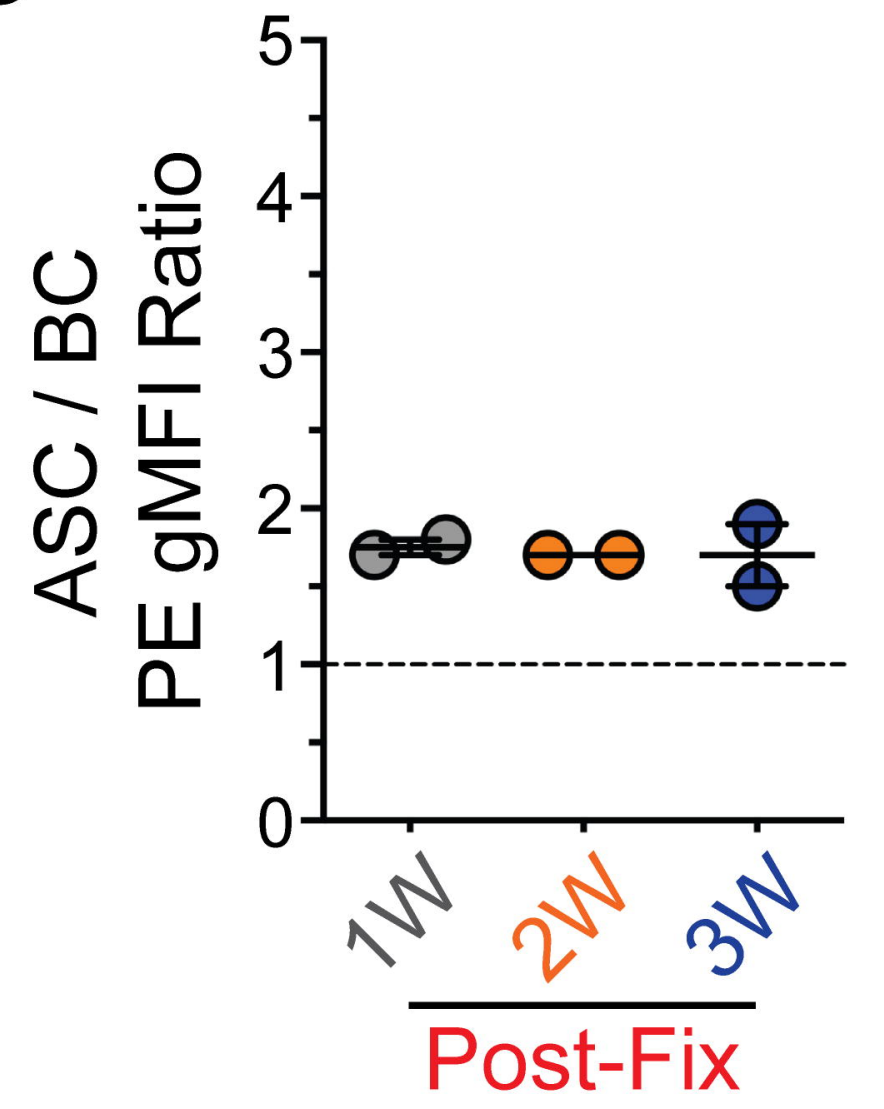

E

$(2 \mathrm{~mL})$

$0.1 \% \mathrm{BSA}(3 \mathrm{~mL})$

F

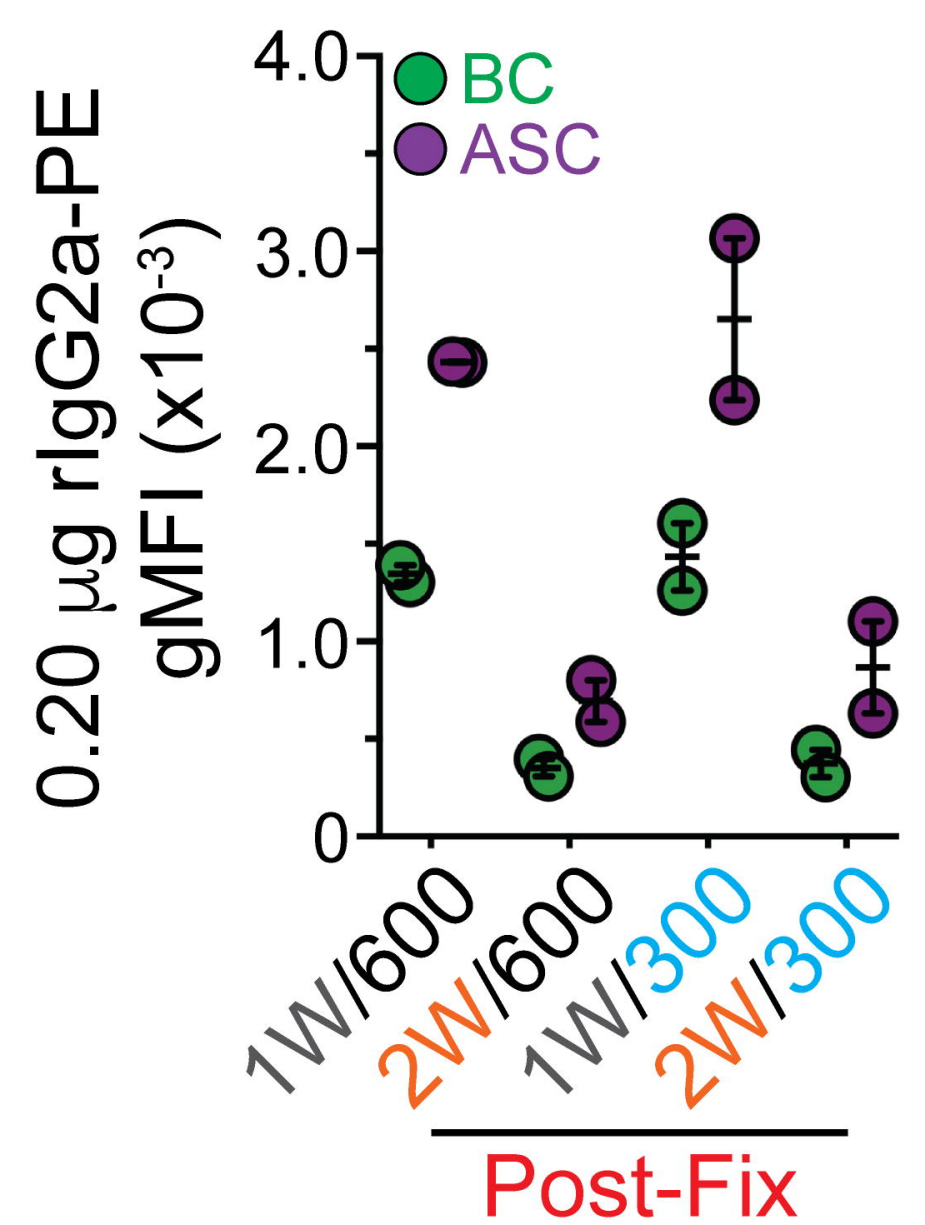

G

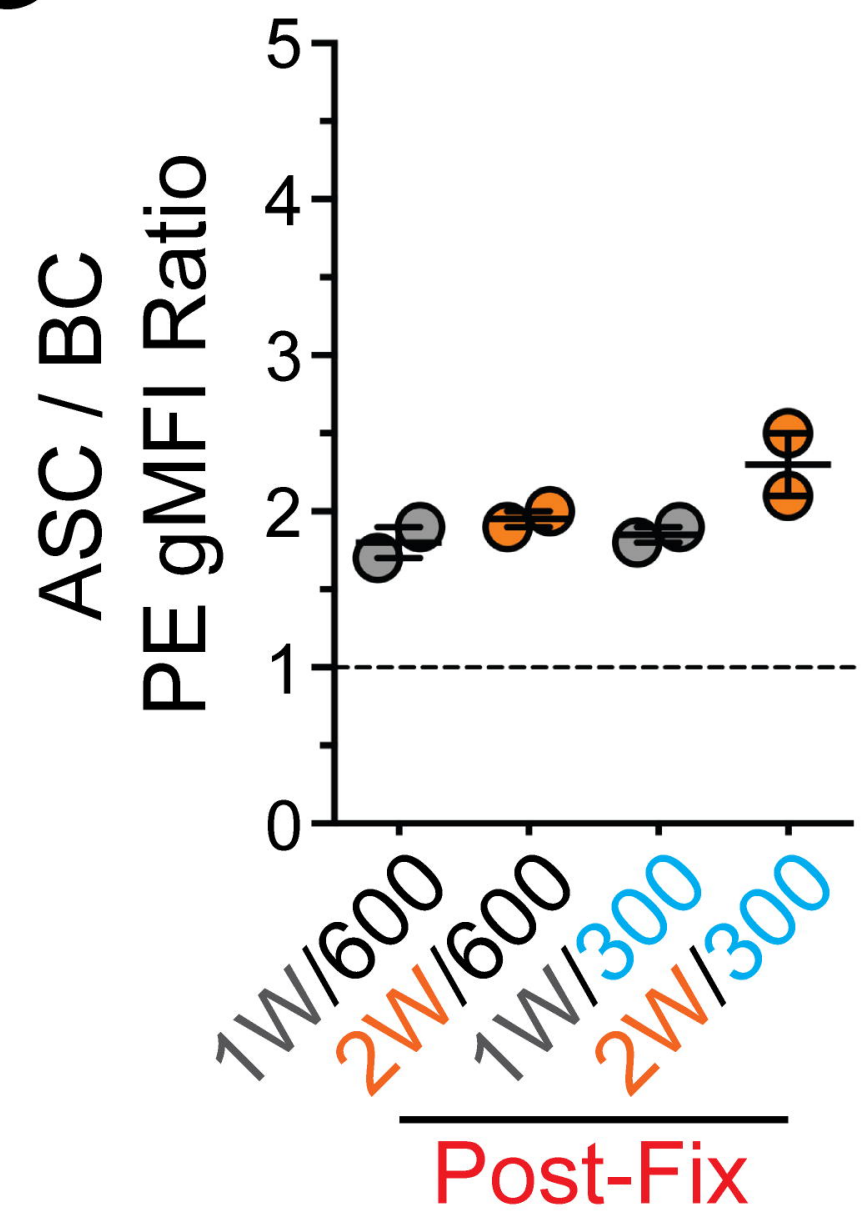


Figure 4

A

PFA+Sap

Total Events BC ASC

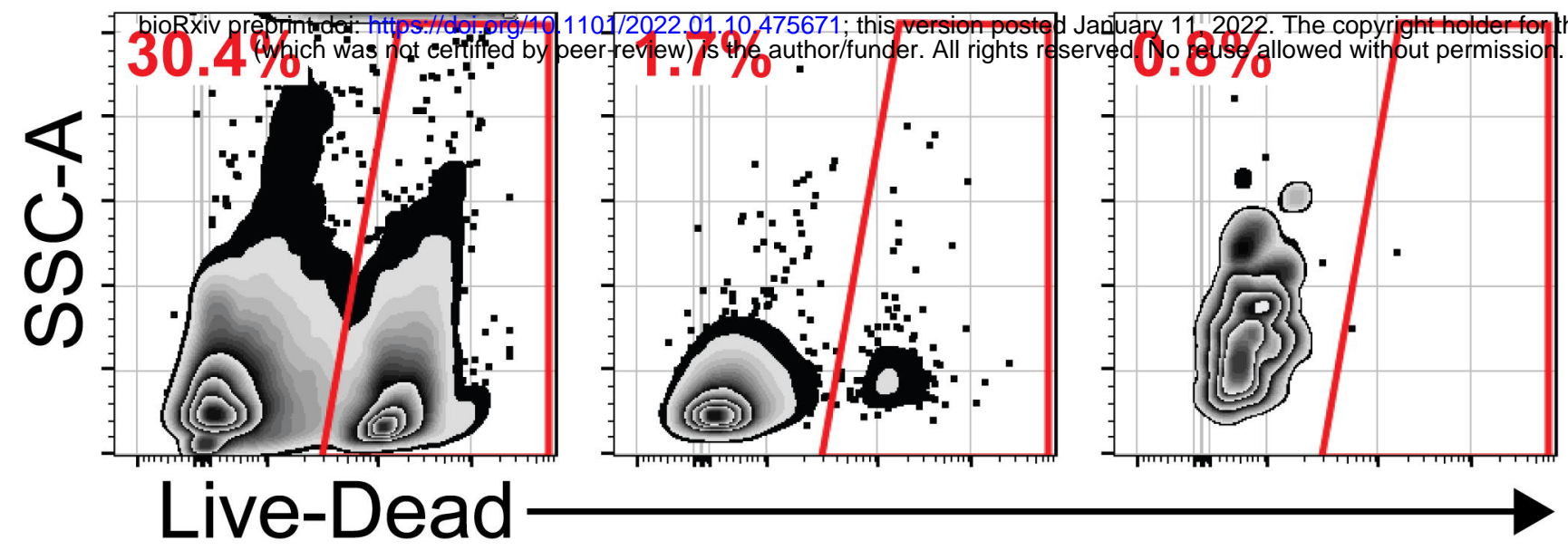

Foxp3

Total Events
$\mathrm{BC}$

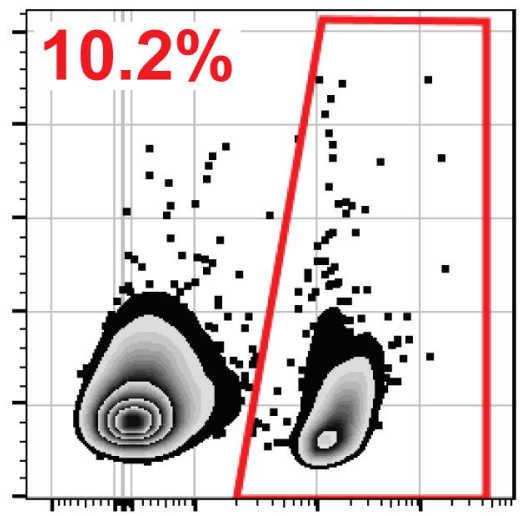

ASC

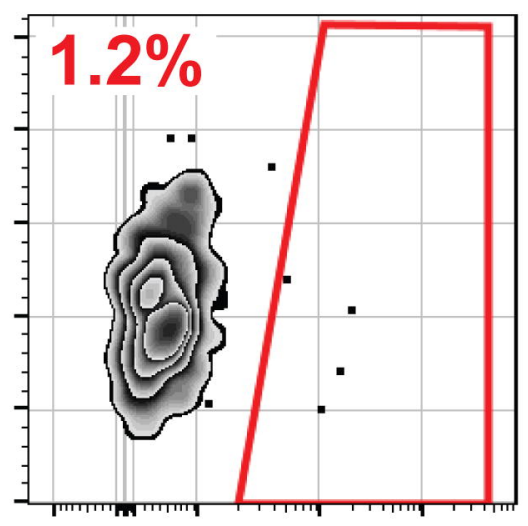

Live-Dead

C

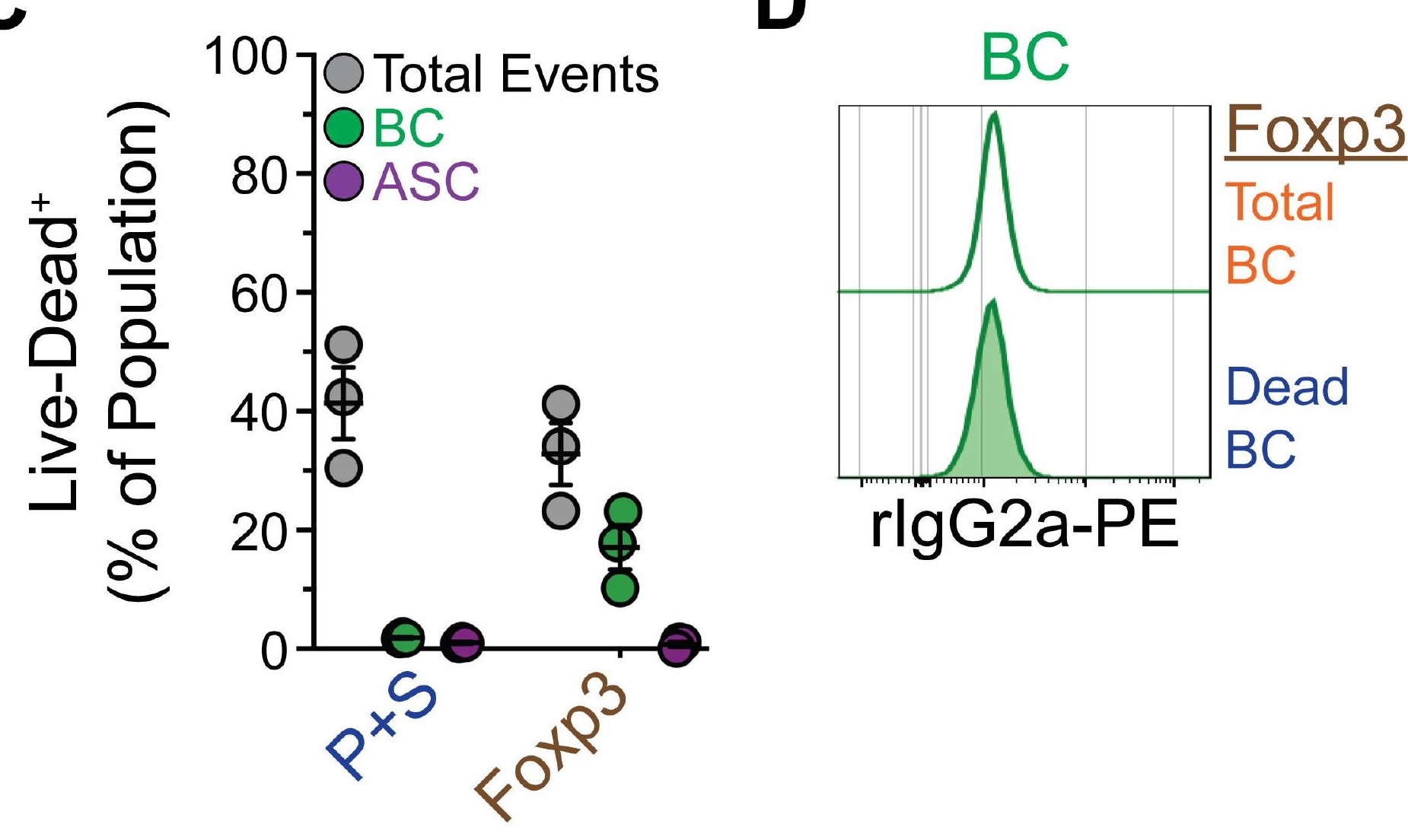


Figure 5

A

1 Wash Post-Fix

$\mathrm{BC}$

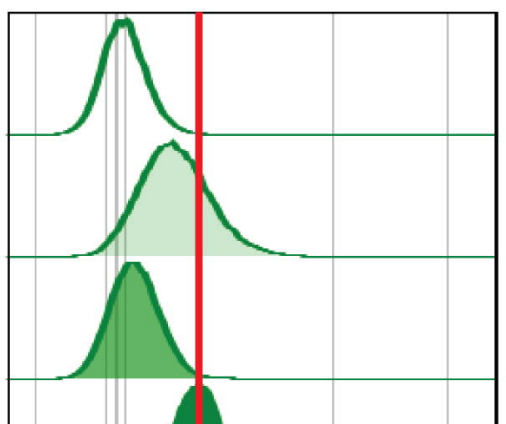

reprint doi: https://doi.oog/

(Which was not certified by peer review) is

Pro-IL-1 $\beta$

ASC
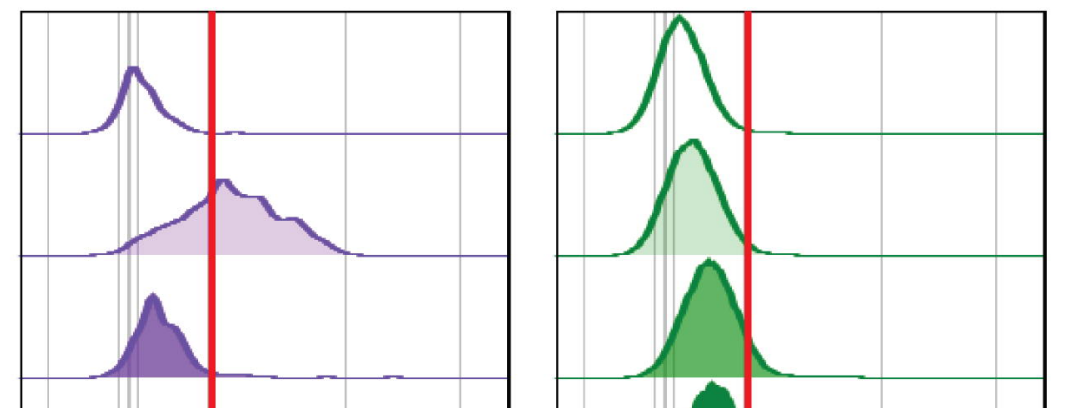

2022. The copyright ho der for this preprin 2 Washes Post-Fix

BC ASC

(rlgG1-PE/Cy7)

1 Wash Post-Fix

2 Washes Post-Fix

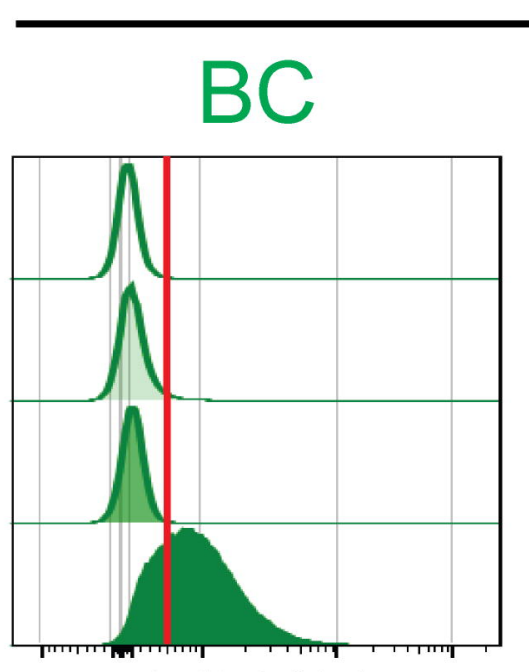

TLR7

(mlgG1-PE)

C

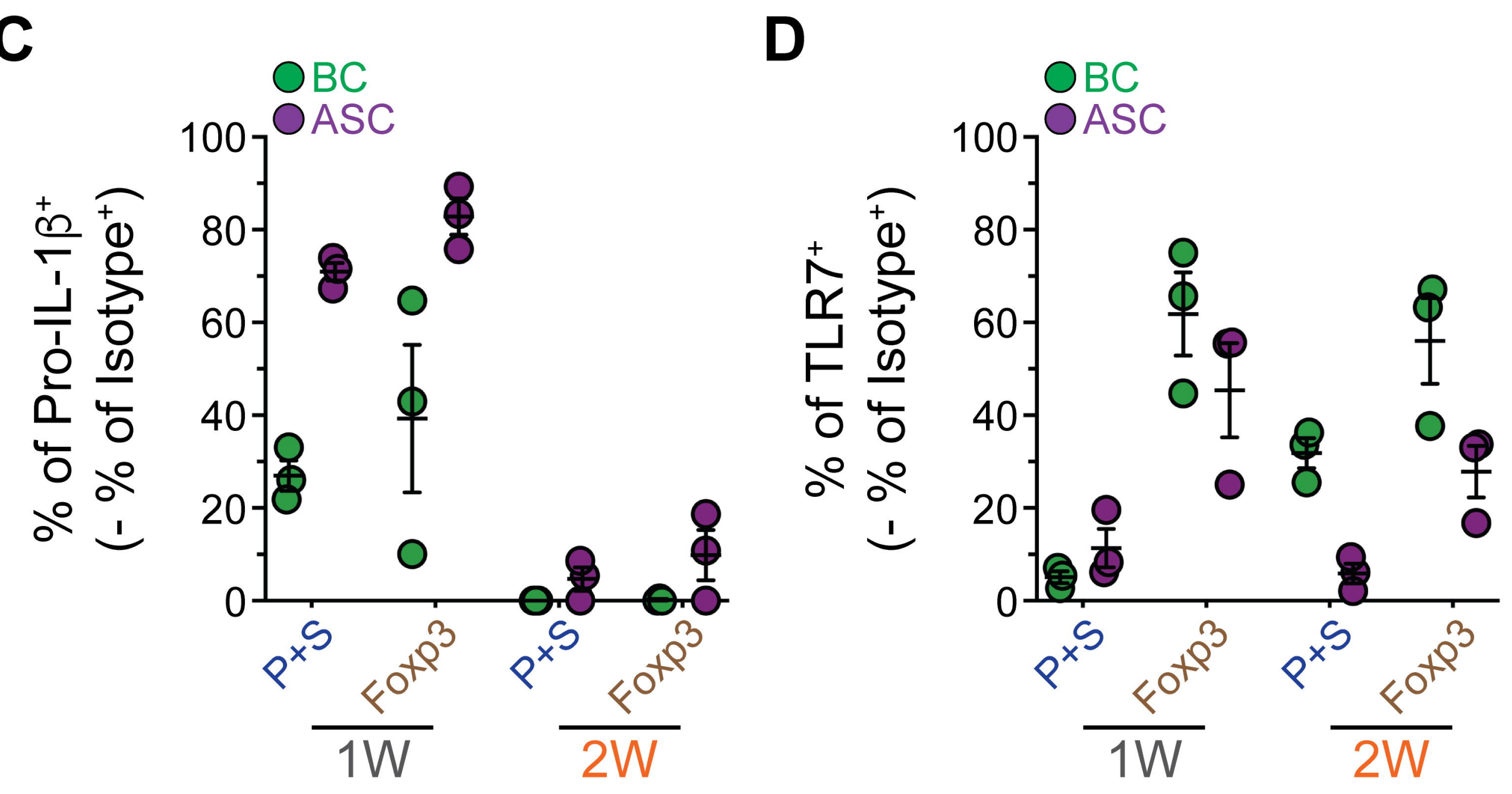

ASC
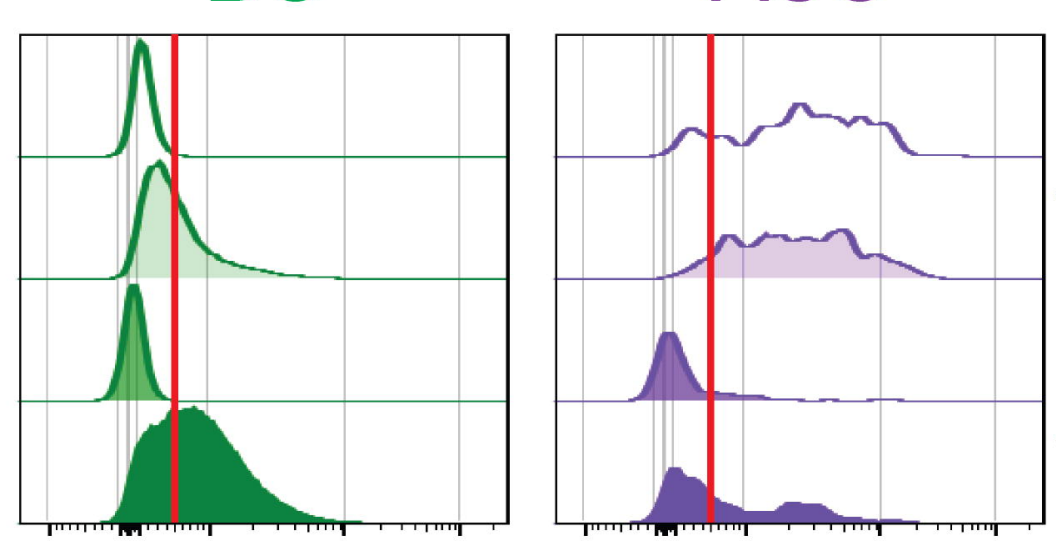

\begin{tabular}{l|l} 
Isotype & PFA+Sap \\
TLR7 & Isotype \\
TLR7 & Foxp3
\end{tabular}

$\mathrm{BC}$

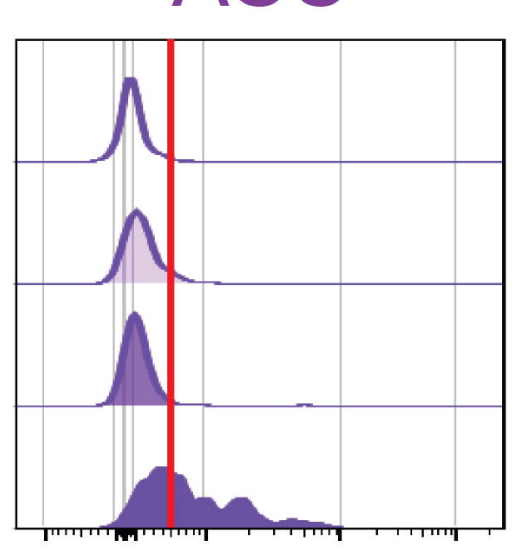

$\longrightarrow$
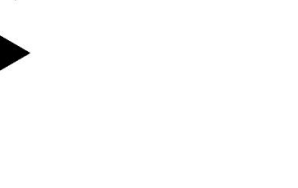

D 